\title{
Discontinuum analysis of the fracture mechanism in masonry prisms and wallettes via discrete element method
}

\author{
Bora Pulatsu ${ }^{1}$, Ece Erdogmus ${ }^{2}$, Paulo B. Lourenço ${ }^{3}$, Jose V. Lemos ${ }^{4}$, and Jim Hazzard ${ }^{5}$
}

\begin{abstract}
This study proposes an alternative approach to modeling the failure mechanisms of brickwork assemblages under combined shear-compression, shear-tension (parallel to bed joints), and compression-flexural loadings using the discrete element method (DEM). In this context, recently developed elastic-softening contact constitutive laws considering the mode-I and modeII fracture energies are implemented into the dynamic solution scheme of the DEM to simulate the mechanical interaction between mortar and masonry units represented via 3D polyhedral blocks. Different experimental studies from the literature are used to validate the proposed computational models, and good agreement is found in terms of strength, material behavior, and fracture mechanisms. The findings of this research indicate that the proposed modeling strategy is successful in predicting the macro behavior of masonry under various complex fracture modes based on the defined micro properties. Sensitivity analyses are also performed by varying the fracture energy and valuable inferences are made with respect to the stress-displacement response and failure mechanisms of masonry.
\end{abstract}

Keywords: DEM, Discontinuum analysis, Masonry, Softening, Contact mechanics

1 Postdoctoral Associate, Architectural Engineering, University of Nebraska-Lincoln, United States ( Corresponding author: bpulatsu@unomaha.edu )

2 Professor, Architectural Engineering, University of Nebraska-Lincoln, United States

3 Professor, Institute for Sustainability and Innovation in Structural Engineering, University of Minho, Guimaraes, Portugal

4 Principal Researcher, Laboratório Nacional de Engenharia Civil, Lisbon, Portugal

5 Principal Engineer, Itasca Consulting Group, Minneapolis, United States 


\section{Introduction}

Masonry is one of the oldest construction techniques and almost every historical structure in the world contains some form of masonry. It is a composite and heterogeneous material, typically made up of units and mortar, but dry-joint masonry without any binding material is also common. Thus, masonry may refer to a single material or a mixture of materials. This study focuses on brickwork assemblages made up of mortar and clay bricks.

The mortar joints are the weak planes in masonry vulnerable to tension and shear forces, and the bond strength (either tension or shear) between the unit and mortar determines the strength of the assembly against out-of-plane or in-plane loads. Cracking in masonry structures may be caused by exterior loads or imposed deformations such as soil settlements, variations in temperature, shrinkage or irreversible expansion or moisture changes when combined with the differences in the mechanical properties of masonry constituents.

It has always been a challenge to predict the strength and fracture mechanism of masonry accurately due to its heterogeneous, nonlinear, and anisotropic nature. Moreover, the arrangement of the masonry units (hereafter referred to as workmanship) also has a considerable influence on the behavior and capacity of masonry structures [1-4]. Over the last several decades, progress has been made in advanced modeling strategies with different levels of complexities to improve the understanding of fracture mechanics of masonry. The current computational models thus far presented in the literature mainly utilize the continuous and discontinuous finite element analysis that can be categorized as macro- and micro-modeling [5]. In macro-modeling the mechanical properties of masonry are smeared as a homogeneous medium, which can be associated with plasticity or damage constitutive laws, [6-8]; while in the micro-modeling, the masonry constituents (mortar and units) and the unit-mortar interface are distinctly represented via different material constitutive models [9-11]. Although the latter approach provides accurate numerical predictions, it requires many input parameters and an intensive computational effort, which detrimentally affects its applicability to large-scale models. To overcome these problems, expanded continuum blocks (representing the masonry units) and interface elements (replicating the mortar and unit-mortar interface) can be considered, referred to as the simplified micromodeling as discussed in [12-14]. 
In addition, discontinuum based methods become an attractive solution since the last several decades to simulate masonry structures, where a system of distinct (or discrete) blocks that may be rigid or deformable are utilized [15-18]. Deformability of the discrete blocks is addressed in combined finite-discrete element method (FDEM), in which the blocks are discretized by linear elastic triangular (2D) or tetrahedral (3D) finite elements, whereas the fracture and joint sliding phenomena are captured using contact elements including mode-I and II fracture energies defined at the contact surface between the adjacent blocks. The numerous applications of FDEM can be found in [19-22].

As an alternative approach, this paper proposes a novel technique to analyze brickwork masonry considering the units and/or the mortar explicitly as a group of 3D polyhedral blocks (referred to as meso-model), interacting along their boundaries within the framework of the discrete element method (DEM). To better represent the mechanical interaction among the distinct blocks, new elastic-softening tension and shear contact models are implemented into a commercial discrete element code, 3DEC, with the user-defined contact constitutive model feature. Using the proposed contact models, it is possible to capture the complete macro behavior of masonry (preand post-peak regime) together with the corresponding deformation behavior. In this context, this research has two main goals:

i) To improve the commonly used Coulomb-slip elasto-plastic contact model employed in current discrete element models $[23,24]$ by taking into consideration of mode-II fracture energy in the contact constitutive law to better capture the post-peak behavior of the material.

ii) To investigate different geometrical representations of masonry assemblages, depending on the examined fracture mechanism (both in- and out-plane-plane), in order to better demonstrate the various failure modes and patterns with the desired level of accuracy.

Previously published experimental protocols are replicated in this study to develop and validate the proposed modeling strategies [25-27]: 1) Shear test of masonry prisms, 2) direct tension test of masonry wallettes and 3) horizontal bending of unreinforced clay brick masonry wallettes. In shear testing, both mortar and unit are replicated explicitly, aiming at a finer model and a discussion of the failure mechanism within the mortar joint itself, whereas in the direct tensile (in which tension and shear of the joints are involved) and flexural testing of masonry wallettes, 
only the masonry units (made up of 3D polyhedral blocks) with zero thickness joints are considered. It is noteworthy that in the shear test of masonry prisms and direct tension test of wallettes, the model width is taken as the $1 / 10$ of the real specimen width in the computational model (e.g., there exists only one block along the width) to reduce the number of blocks through the out-of-plane direction and eliminate the unpractical computational time [28]. Also, the application of external loads and the failure mode of those experiments are essentially in-plane. On the other hand, the horizontal bending test of masonry wallettes is analyzed considering all three dimensions of the specimen to demonstrate the applicability of the proposed modeling strategy in both cases.

In the next section, the theoretical background and the application of the discontinuum models are presented.

\section{Background}

The masonry prisms and wallettes are considered as structural systems consisting of 3D deformable distinct polyhedral blocks, mechanically interacting with each other, based on the discrete element method (DEM) developed by Cundall [29]. The randomly generated blocks are used to replicate mortar or masonry units to simulate different mechanical tests of masonry specimens via discontinuum-based formulation. All discrete element models are created using a commercial discrete element code, 3DEC developed by ITASCA, while 3D polyhedral blocks, generated based on a Laguerre tessellation, are obtained via an open-source software package, NEPER. Interested readers are referred to [30-32].

The main advantages of the applied discontinuum analysis are summarized as follows; i) DEM captures the localized cracks that may happen within the unit mortar or even mortar-unit interface in masonry. Furthermore, discrete element formulation can be expressed both in the simplified and detailed mesoscale depending on the analysis goals ii) DEM can capture the rotations and deformations occurring between the adjacent blocks by only relying on the interaction forces between them using an explicit solution scheme. Therefore, there are no special crack tracking algorithms and material property updates needed. 
Through this research, two different representations of masonry are proposed based on the observed fracture mechanisms of masonry specimens during the experiments that are given in the reference studies. In the shear test, continuum blocks are used to replicate masonry units, whereas the mortar is replicated via a discontinuous system of polyhedral blocks (Figure 1a). On the other hand, to better represent the fracture in masonry units in direct tensile and flexural tests of masonry wallettes, polyhedral blocks are utilized to replicate masonry units, whereas the mortar joints are represented as zero-thickness interfaces (Figure 1b). In both computational models, the number of blocks is arranged depending on the desired resolution in the fracture pattern and computational cost.

\subsection{Numerical Procedure}

In DEM, each polyhedral block is subdivided into an internal finite volume mesh using constant strain tetrahedral elements with a linearly elastic material constitutive model, as shown in Figure 1b. Furthermore, the mechanical interaction between adjacent blocks develops by orthogonal springs with a nonlinear force-displacement law relying on the set of point contacts (see Figure 1b). Different from discontinuous finite element models using interface or joint elements, contact points are automatically recognized for the nodal points of the internal element mesh that coincidences on block boundaries [33]. In 3DEC, the contact detection logic utilizes the concept of common plane between the blocks, where the gap and/or overlap between the blocks is traced during calculation procedure. For a comprehensive study about the contact detection algorithm, readers are referred to [34].

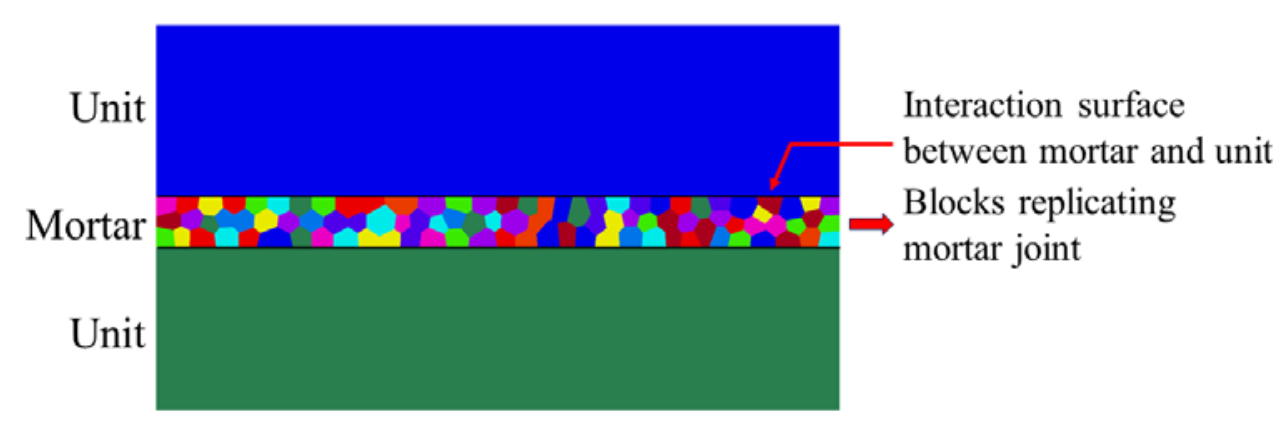

a) Discontinuum model used in the shear test. 


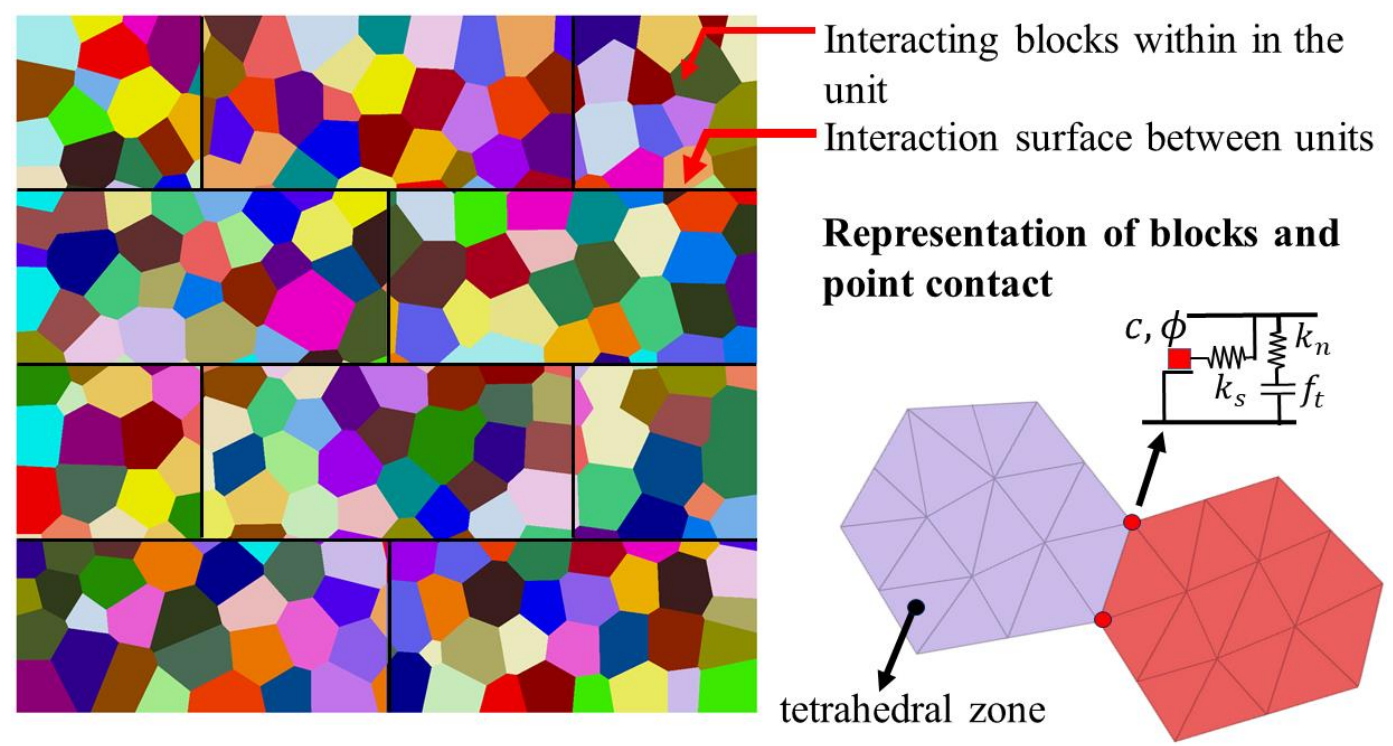

b) Discontinuum model used in the tensile test of wallette parallel to bed joints and representation of point contact.

Figure 1. Discrete meso-models utilized in the simulation of shear and tensile behavior in masonry prisms and wallettes.

The dynamic solution scheme of DEM is based on the integration of the equations of motion using the explicit finite difference method as given in Equation 1, which is solved for each gridpoint. Note that the time step $\Delta t$ is divided into mid-intervals and the next $(t+\Delta t / 2)$ and previous $(t-\Delta t / 2)$ time steps are indicated as $t^{+}$and $t^{-}$, respectively.

$$
\begin{gathered}
\dot{u}_{i}^{t+}=\dot{u}_{i}^{t-}+\left\{\Sigma F_{i}^{t}-\left(F_{d}\right)_{i}\right\} \frac{\Delta t}{m_{n}} \\
\Sigma F=F_{\text {gravity }}+F_{\text {contact }}+F_{\text {external }}+F_{\text {internal }} \\
\left(F_{d}\right)_{i}=\xi\left|\Sigma F_{i}^{t}\right| \operatorname{sgn}\left(\dot{u}_{i}^{t-}\right)
\end{gathered}
$$

where $\dot{u}, F, F_{d}$ and $m_{n}$ are velocity, resultant of all external forces applied to the gridpoint, damping force and nodal mass, respectively. As can be seen from the given formulation, the damping is adjusted proportional to the local unbalanced force, (simply $\Sigma F$ corresponding to gridpoint) [35], according to the sign of the velocity, where $\operatorname{sgn}(\zeta)=1$, if $\zeta \geqslant 0 ; \operatorname{sgn}(\zeta)=-1$, if $\zeta<0$. The total force vector includes gravity forces $F_{\text {gravity }}$, sub-contact forces $F_{\text {contact }}$ (existing 
only for gridpoints along the block boundary), externally applied loads $F_{\text {external }}$, and contribution to the internal stresses in the zones adjacent to the grid point $F_{\text {internal }}$. Note that contribution to the internal stresses in the zones adjacent to the grid point can be obtained as,

$$
F_{\text {internal }}=\int_{S} \sigma_{i j} n_{j} d s
$$

where, $\sigma_{i j}$ and $n_{j}$ indicate the zone stress tensor and unit outward normal to the surface. To improve the convergence of numerical solutions, scaled masses and local damping formulation are used during the quasi-static analyses [36]. It should be noted that, in the local damping formulation, given by Equation 3, different amount of damping is required for different parts of the numerical model to tackle the abrupt load changes and capture progressive failure mechanisms. Hence, the amount of damping varies in the model [37]. The damping constant, $\xi$ (default value is 0.8 in $3 \mathrm{DEC}$ ), is dimensionless and it is independent of material properties or given boundary conditions.

From the integration of the equations of motion, new block positions are found. Then, examining the relative displacements (in normal $\Delta u_{n}$ and shear $\Delta u_{s}$ directions) between the blocks that are in contact, the elastic normal $(\Delta \sigma)$ and shear $(\Delta \tau)$ stress increments are calculated. In the elastic range, the behavior of the contact is governed by normal $\left(k_{n}\right)$ and shear $\left(k_{s}\right)$ stiffnesses, given in Equation 5 and 6, respectively. Afterward, the obtained stress increments are added to the previous contact stresses and corrected according to the assigned failure criteria, which are utilized in the next time step.

$$
\begin{gathered}
\Delta \sigma=k_{n} \Delta u_{n} \\
\Delta \tau=k_{s} \Delta u_{s}
\end{gathered}
$$

In the simplest contact model, the nonlinear response of the joints is controlled by the tensile strength $\left(f_{t}\right)$ in the normal direction (Equation 7) and Coulomb-slip joint model in shear direction (Equation 8), which requires cohesion $(c)$ and friction angle $(\phi)$ as inputs. 


$$
\begin{gathered}
\sigma \leq f_{t} \\
|\tau| \leq c+\sigma \tan \phi
\end{gathered}
$$

Calculated sub-contact stresses are multiplied with the assigned contact area $\left(A_{c}\right)$, to be incorporated in Equation 1 as $F_{\text {contact }}$. Note that the contact area is equal to $1 / 3$ of the areas of the surrounding triangular faces containing the sub-contact. Additionally, dilatancy is considered when the shear failure is identified at the contact by introducing the dilation angle $(\psi)$, as shown in Equation 9. Subsequently, the normal stress is updated based on the influence of dilation using Equation 10.

$$
\begin{gathered}
\Delta u_{n, \text { dilation }}=\Delta u_{s} \tan \psi \\
\Delta \sigma_{\text {total }}=\Delta \sigma+k_{n} \Delta u_{s} \tan \psi
\end{gathered}
$$

Hence, at each time step, equations of motion and stress-displacement laws are applied. To ensure the numerical stability, the critical time step $\left(\Delta t_{c}\right)$ is set with respect to the smallest nodal mass $(m)$ and the maximum contact stiffness $(k)$ in the system as follows,

$$
\Delta t_{c}=2(\text { frac })\left(\frac{m}{k}\right)^{1 / 2}
$$

where the term frac is the user-defined constant (default value, 0.1). Finally, the explained computational procedure of DEM is summarized in Figure 2, where the successive calculations are provided. 


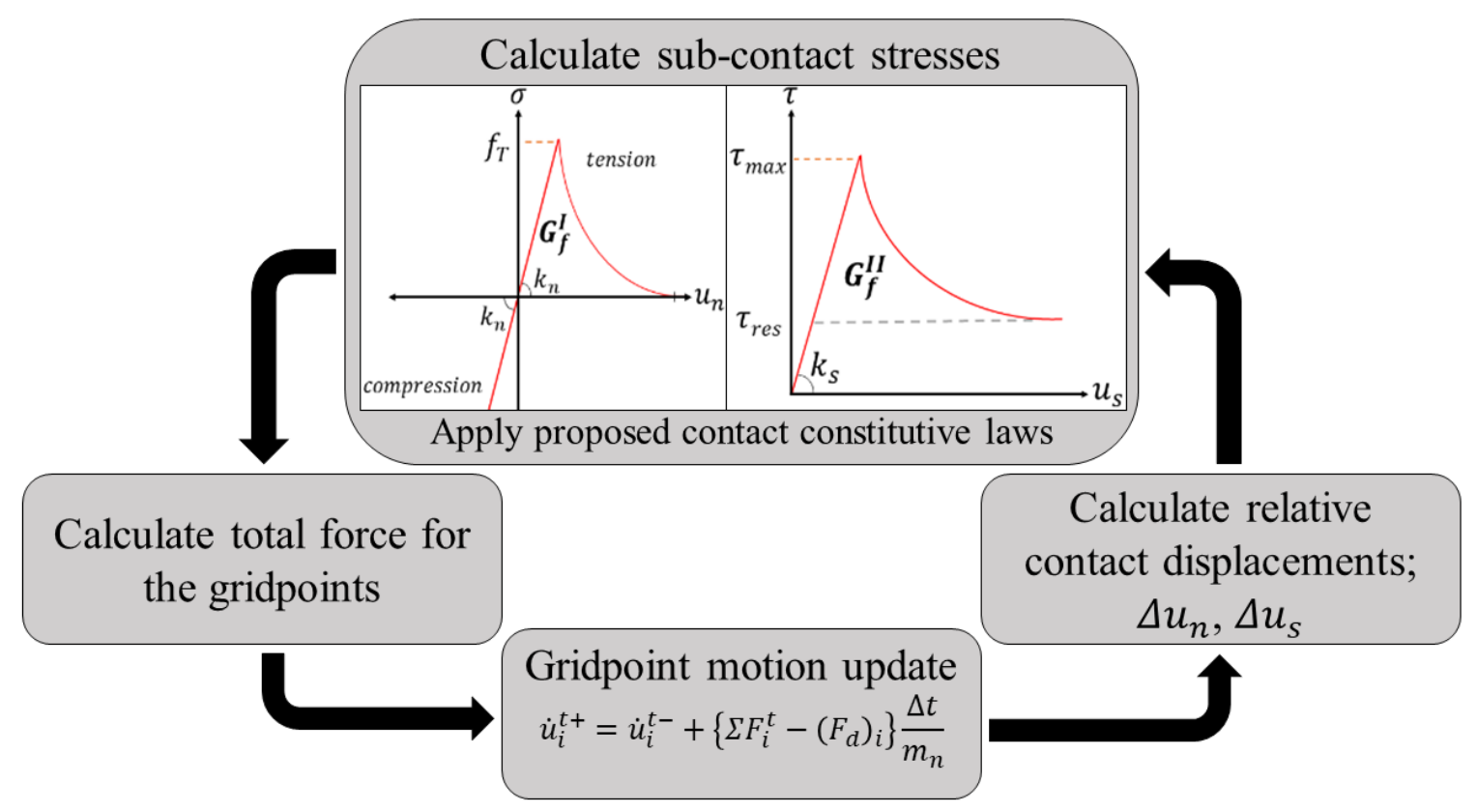

Figure 2. Dynamic calculation scheme of DEM.

\section{Proposed Contact Models}

According to the point contact approach mentioned above, the stress at the contact point is calculated as a function of relative block displacement at that contact [38]. However, it is worth noting that the widely used simple Coulomb constitutive model with tension cut-off, assuming a brittle failure mode, does not entirely capture the fracture energy observed in actual masonry assemblies and constituents subjected to loading. Also, it does not provide the post-peak response of the material accurately and may cause block size dependent results [39]. In this context, novel elastic-softening contact models, taking into consideration of mode I and II fracture energies in their constitutive law, have been embedded in 3DEC software [40]. A stress update routine is implemented into the explicit time integration scheme of the numerical procedure, where new contact stresses are corrected, if there is a failure, according to the proposed contact stressdisplacement functions.

Three contact models are developed and applied in this research. First, a linear softening behavior is given for both tension (Equation 12) and shear (Equation 13) as the most straightforward contact constitutive law, where the current normal and shear displacements are 
denoted as $\left(u_{n}\right)_{c}$ and $\left(u_{s}\right)_{c}$, respectively. In addition, peak and residual shear resistances are designated as $\tau_{\text {max }}$ and $\tau_{\text {res }}$, which are also shown in Figure 3.

$$
f_{t}=f_{T}\left(1+\frac{\left(u_{n}\right)_{c}-\frac{f_{T}}{k_{n}}}{\frac{f_{T}}{k_{n}}-\frac{2 G_{f}^{I}}{f_{T}}}\right)
$$

where $f_{t}, f_{T}$ and $G_{f}^{I}$ correspond to updated tensile strength, initial tensile strength, and tensile fracture energy at the contact, respectively.

$$
\begin{gathered}
u_{l}=\frac{2 G_{f}^{I I}}{\tau_{\max }-\tau_{\text {res }}}+\frac{\tau_{\text {res }}}{k_{s}} \\
c_{c}=c_{0}+\left(c_{0}-c_{r e s}\right)\left(\frac{\left(u_{s}\right)_{c}-\frac{\tau_{\max }}{k_{s}}}{\frac{\tau_{\max }}{k_{s}}-u_{l}}\right) \\
\tan \phi_{c}=\tan \phi_{0}+\left(\tan \phi_{0}-\tan \phi_{r e s}\right)\left(\frac{\left(u_{s}\right)_{c}-\frac{\tau_{\max }}{k_{s}}}{\frac{\tau_{\max }}{k_{s}}-u_{l}}\right) \\
\tau_{c}=c_{c}+\sigma \tan \phi_{c}
\end{gathered}
$$

where $c_{0}, c_{r e s}, c_{c}, \tau_{c}$ and $G_{f}^{I I}$ are initial cohesion, residual cohesion, current (or degraded) cohesion, updated shear stress and shear fracture energy at the contact, respectively. 

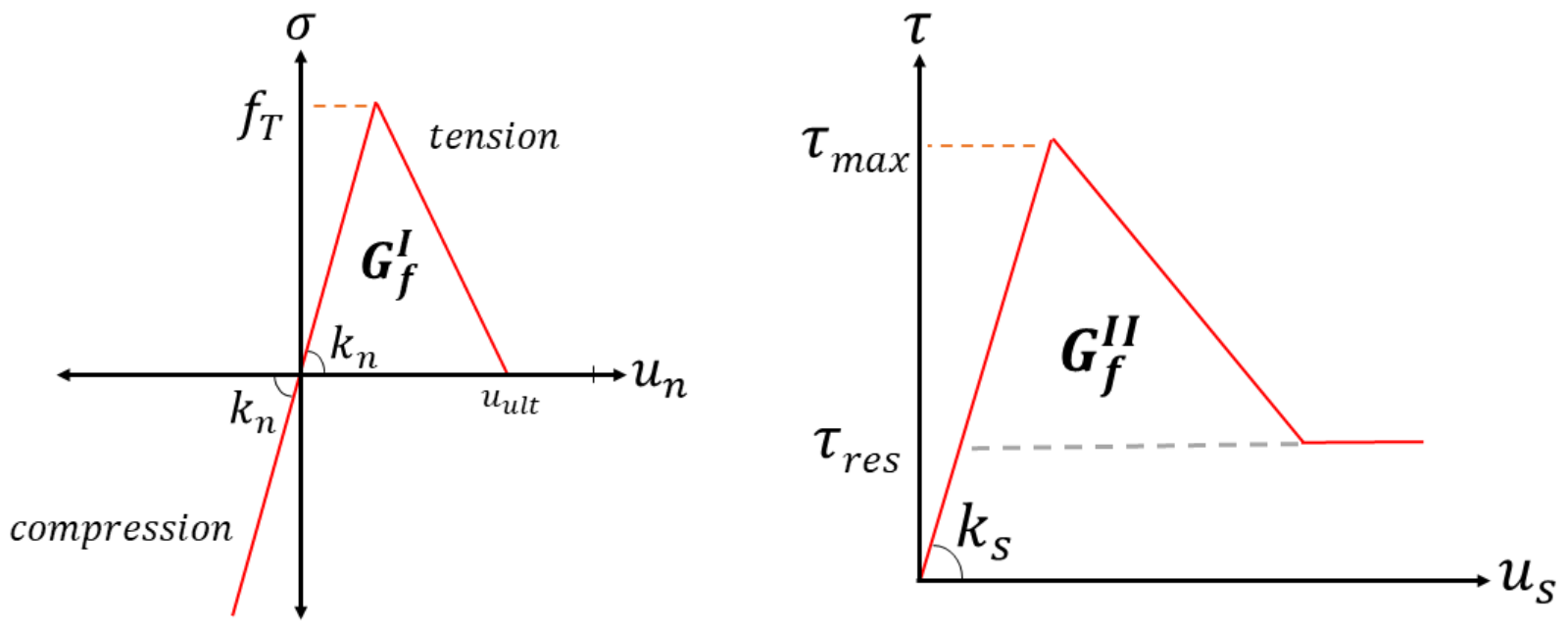

Figure 3. Linear elastic-softening contact constitutive models in tension (left) and shear (right).

In the second constitutive model, a polynomial softening behavior is considered in tension (Equation 14), where the order of the stress-displacement function $(\alpha)$ is required to be specified by the user. It is important to note that the degree of the polynomial function may be arranged to best fit the experimental data of the material at the contact.

$$
f_{t}=f_{T}\left(\frac{\frac{2 G_{f}^{I}}{f_{T}}}{\frac{2 G_{f}^{I}}{f_{T}}-\frac{f_{T}}{k_{n}}+\left(u_{n}\right)_{c}}\right)^{\alpha}
$$

Similarly, a polynomial softening model in shear is presented in Equation 15 including the mode II fracture energy $\left(G_{f}^{I I}\right)$. Again, the degree of the polynomial function $(\beta)$ is left to the user to determine based on the available experimental data. A typical polynomial softening behavior in tension and shear is shown in Figure 4. It is worth noting the proposed contact models has no capability to capture snap-back response. 


$$
\begin{gathered}
\lambda=\left(\frac{\left(u_{s}\right)_{c}}{\frac{2 G_{f}^{I I}}{\tau_{\max }}-\frac{\tau_{\max }}{k_{s}}+\left(u_{s}\right)_{c}}\right)^{\beta} \\
c_{c}=c_{r e s}+\lambda\left(c_{0}-c_{r e s}\right) \\
\tan \phi_{c}=\tan \phi_{0}+\lambda\left(\tan \phi_{0}-\tan \phi_{r e s}\right) \\
\tau_{c}=c_{c}+\sigma \tan \phi_{c}
\end{gathered}
$$
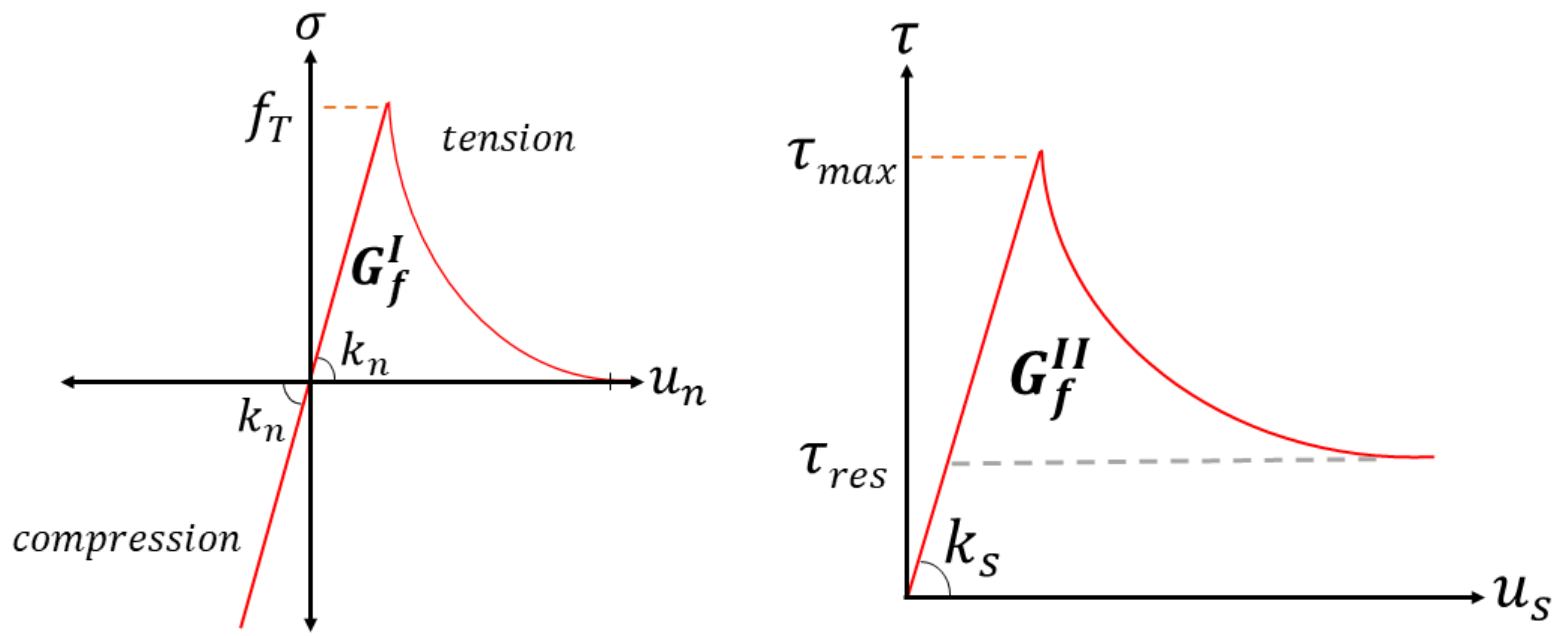

Figure 4. Polynomial elastic-softening contact constitutive models in tension (left) and shear (right).

Finally, in the third constitutive model, exponential softening is implemented in tension (Equation 16) and shear (Equation 17), which is given by Lourenço [13].

$$
f_{t}=f_{T} e^{-\left(\frac{f_{T}}{G_{f}^{I}}\left(\left(u_{n}\right)_{c}-\frac{f_{T}}{k_{n}}\right)\right)}
$$




$$
\begin{gathered}
c_{c}=c_{r e s}+\left(c_{0}-c_{r e s}\right) e^{-\left(\frac{c}{G_{f}^{I I}}\left(\left(u_{s}\right)_{c}-\frac{\tau_{m a x}}{k_{s}}\right)\right)} \\
\tan \phi_{c}=\tan \phi_{r e s}+\left(\tan \phi_{0}-\tan \phi_{r e s}\right)\left(1-\frac{c_{0}-c_{c}}{c_{0}-c_{r e s}}\right) \\
\tau_{c}=c_{c}+\sigma \tan \phi_{c}
\end{gathered}
$$

In the following sections, applications of the proposed linear, polynomial and exponential softening models are provided. Three benchmark experiments are considered to validate the proposed contact models: the shear test presented by Pluijm [26], the horizontal tensile test of masonry wallettes discussed in [25] and horizontal bending test of unreinforced masonry units given in $[27,41]$. Finally, a set of sensitivity analyses is performed on the input parameters to demonstrate the influence of the examined properties on the macro behavior of the model.

\section{Behavior of masonry prisms under combined shear and compression}

Masonry structures are exposed to shear stresses when they are subjected to in-plane lateral loading, e.g., due to seismic loads, wind pressures, etc. However, the majority of masonry assemblies are subjected to combined shear-compression loading due to the geometry, a certain degree of confinement at the boundaries or gravitational loading. As a result of this, understanding the complex shear-compression mode (applied shear loading is accompanied by normal stresses at the joint) has been the main interest in shear testing of masonry since the early 1970s. Discussion about the various shear test setups can be found in [42]. It should also be noted that it is a difficult task to design a shear test configuration, where uniform normal and shear stress distributions along the bed joint are always guaranteed. In the case of non-uniform stress-state during the shear loading, the overturning moment along the bed joint may develop and lead to false characterization of the mechanical properties. Furthermore, displacement-controlled (or deformation controlled) tests are essential to extract the softening behavior of the material due to the gradual degradation of cohesion. 
In this study, the couplet testing arrangement designed by Pluijm [26] is utilized to validate the proposed elastic-softening point contact models using a simple discontinuum model composed of two discrete blocks interacting along one contact surface. The main reason to analyze two blocks rather than a discrete meso-model (mentioned earlier) at this stage is to have a clear understanding of the contact behaviors using relatively simple geometry. In Figure 5, the unique test arrangement and the discrete element model are illustrated. In the referenced experimental study, masonry specimens consist of two wire cut clay bricks and mortar with a composition of 1:2:9 (Ordinary Portland Cement: Lime: Sand). The couplets have clay bricks with dimensions of $200 \mathrm{~mm} \times 50$ $\mathrm{mm} \times 50 \mathrm{~mm}$ and $15 \mathrm{~mm}$ mortar thickness. Three different levels of confining (compressive) stresses $(0.1,0.5$ and $1.0 \mathrm{MPa})$ were applied on the specimens during the experiment and a linear approximate function was derived for mode II fracture energy, which depends on the vertical precompressive stress as given in Table 1 [43].

In discontinuum analysis, confining stress is applied on the top surface of the upper block and it is exposed to velocity boundary condition equals to $0.1 \mathrm{~mm} / \mathrm{s}$ while the bottom brick is fixed. The contact stiffnesses are assumed as $150 \mathrm{GPa} / \mathrm{m}$ and $70 \mathrm{GPa} / \mathrm{m}$ for tension $\left(k_{n}\right)$ and shear $\left(k_{s}\right)$ respectively, whereas the nonlinear contact parameters are taken from the experiment that is summarized in Table 1. Identical macro elastic stiffness of the clay brick $\left(E_{b}: 16.7 \mathrm{GPa}\right)$ is used in the discrete blocks as given in [44]. The dilatancy angle is assumed as zero.

Table 1. Contact parameters used in the discontinuum analysis.

\begin{tabular}{cccc}
$c_{0}(\mathrm{MPa})$ & $\tan _{0}$ & $\tan \phi_{\text {res }}$ & $G_{f}^{I I}(\mathrm{~N} / \mathrm{mm})$ \\
\hline 0.87 & 1.01 & 0.73 & $0.058-0.13 \sigma$
\end{tabular}



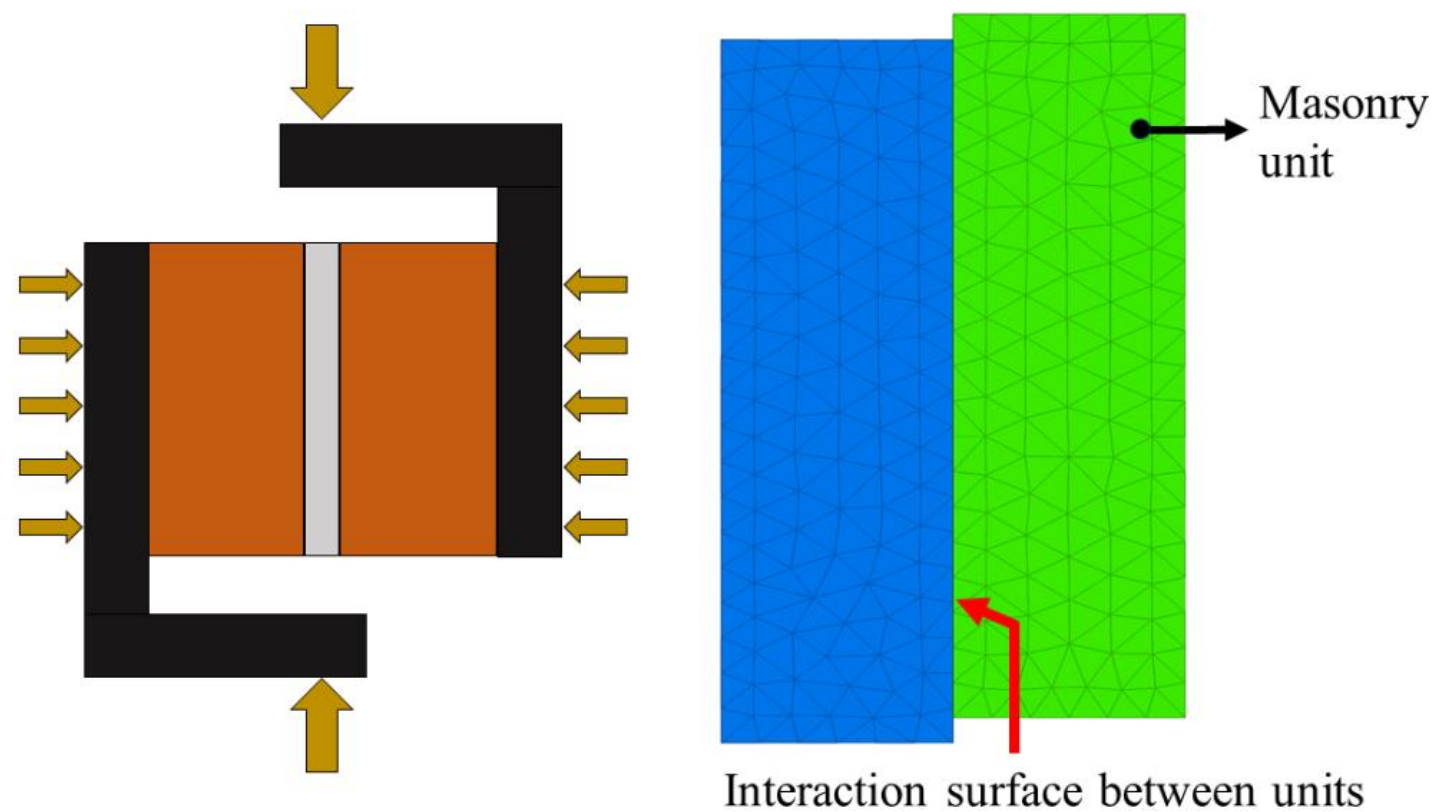

Figure 5. Left: Shear test arrangement developed by Pluijm [26]; Right: Discrete element model consisting of two blocks with the contact surface.

In Figure 6, the numerical predictions are compared with the experimental results that are given as an envelope of three tests. All three contact models estimate well the capacity and residual plateau with comparatively different stress-displacement behaviors as expected. It is worth noting that depending on the desired level of accuracy in the stress-displacement relationship, each contact model may have a valid application field in discrete modeling strategy. However, since the polynomial softening contact model requires more input parameters, namely $\alpha$ and $\beta$, compared to linear and exponential softening, it may be less practical in the absence of experimental data. In that situation, the degree of the polynomial function may be determined within the range of 2 to 3 in the numerical model. In this study, $\beta$ value is taken as 2.1 and 2.9 for the confining stress level of 0.1 and $1.0 \mathrm{MPa}$, respectively. 


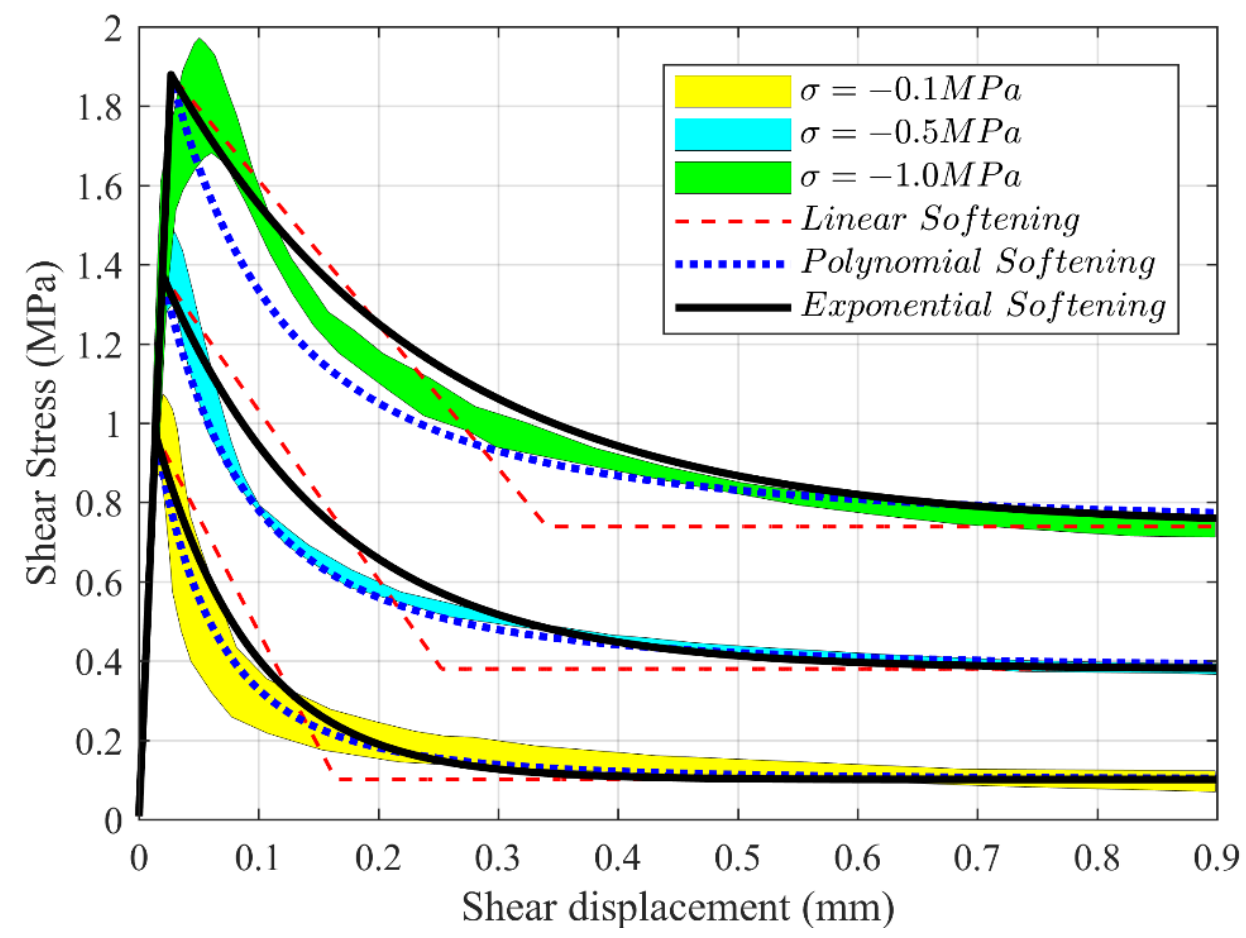

Figure 6. Comparison of experimental results and numerical predictions using simplified discrete element model with different softening contact models in shear.

Thus, in the following analyses utilizing the discrete meso-models, exponential softening is employed since it fits better to experimental results and requires less parameters (previously given in Table 1), compared to the polynomial model.

Depending on the mechanical properties of the brick, mortar and brick-mortar interface, the failure may occur at the interface, mortar joint or combination of both. The presented simple two-block discontinuum analysis is practical and computationally advantages, but it does not provide any information about the failure mode of the mortar. Therefore, the same shear testing configuration is analyzed numerically via discrete meso-models that represent the mortar joint explicitly, to capture more sophisticated failure patterns and simulate the tensile cracks in the mortar joint. There are two models, referred to as coarse and medium, analyzed and compared with the experimental results, as shown in Figure 7 and Figure 8. Macro elastic properties (Young's modulus and Poisson's ratio) are used to predict contact stiffnesses in normal $\left(k_{n}\right)$ and shear $\left(k_{s}\right)$ directions using Equation 18 [45]. 


$$
k_{n}=E / t, k_{s}=G / t
$$

where $t$ indicates the average thickness of the fracture zone. For instance, in meso model composed of coarse blocks, the average thickness is predicted as $4 \mathrm{~mm}$, corresponding to 100 blocks. In addition, relatively high elastic stiffness (10 times higher than the macro elastic stiffness of masonry constituents, where $E_{\text {unit }}: 16.7 \mathrm{GPa}$ and $E_{\text {mortar }}: 2.9 \mathrm{GPa}$ ) is assigned for deformable polyhedral blocks, which may also be called as semi-rigid blocks, to control the governing deformation and nonlinear behavior of the numerical model via discontinuities [46]. The identical nonlinear contact properties are employed in both meso-models (taken from the reference experiment and related published studies $[13,26,44])$ that are given in Table 2 . There is a good agreement found between the proposed nonlinear discrete element models and the experimental results not only in terms of capacity but also in the post-peak behavior of the material (Figure 7). Furthermore, similar failure mechanisms are obtained compared to the shear test of masonry specimens, shown in Figure 8a-b.

Table 2. Contact properties used in the meso-model

\begin{tabular}{cccccc}
$c_{0}(\mathrm{MPa})$ & $\tan \phi_{0}$ & $\tan \phi_{\text {res }}$ & $f_{T}(\mathrm{MPa})$ & $G_{f}^{I}(\mathrm{~N} / \mathrm{mm})$ & $G_{f}^{I I}(\mathrm{~N} / \mathrm{mm})$ \\
\hline 0.87 & 1.01 & 0.73 & 0.60 & 0.01 & $0.058-0.13 \sigma$
\end{tabular}

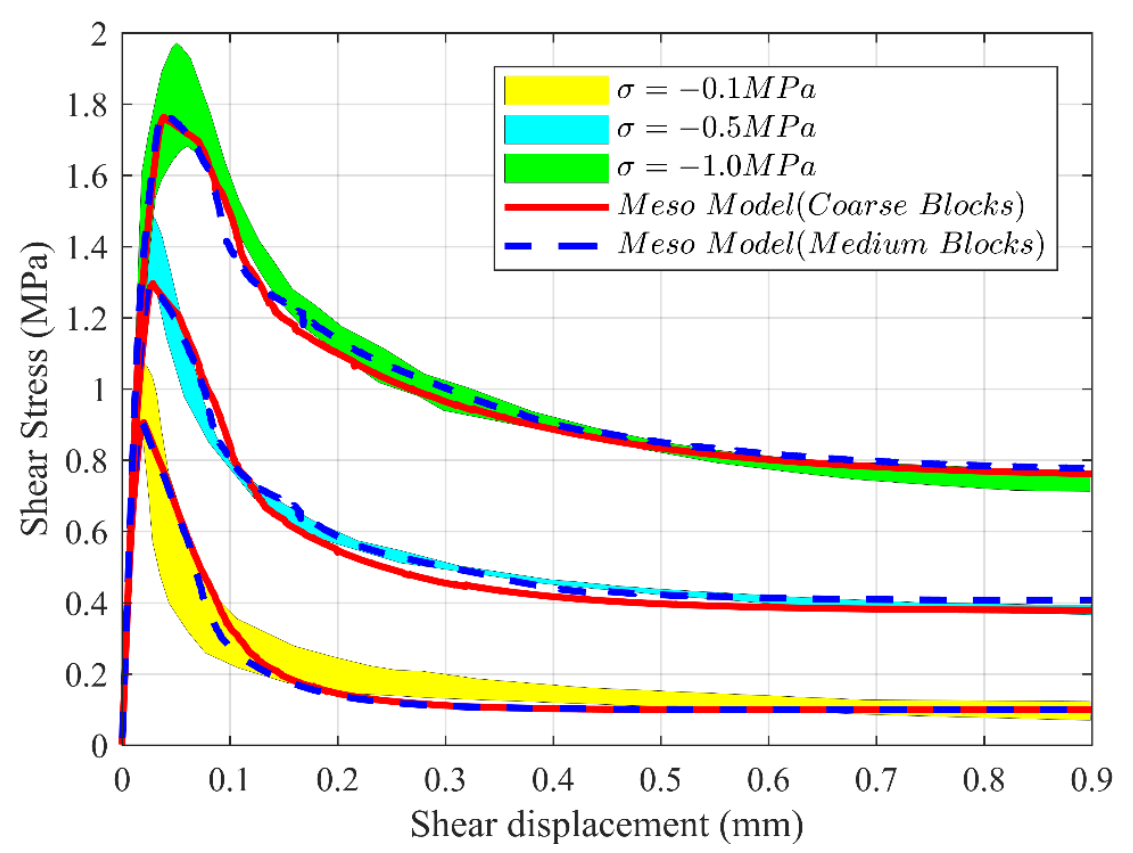

Figure 7. Comparison between discrete meso-models and experiment. 


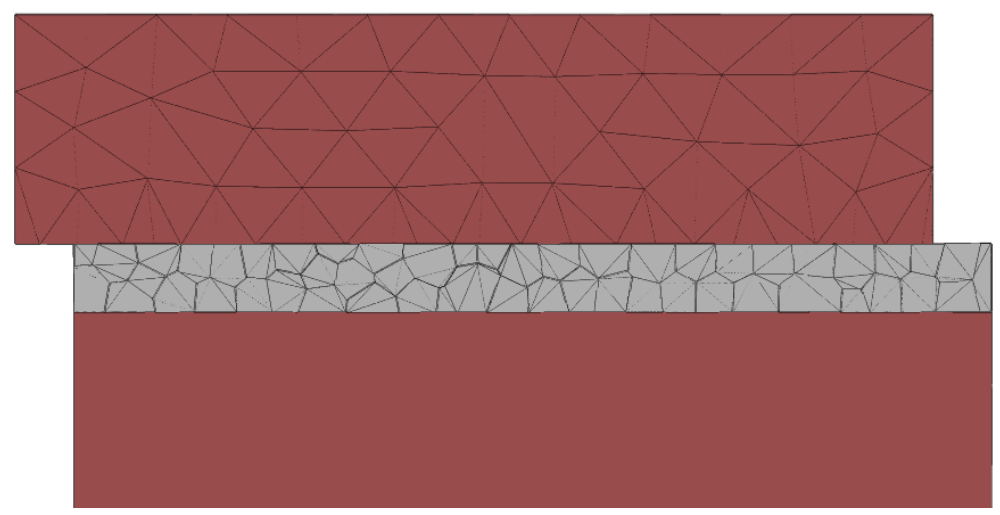

a) Coarse mortar under normal stress $0.1 \mathrm{MPa}$

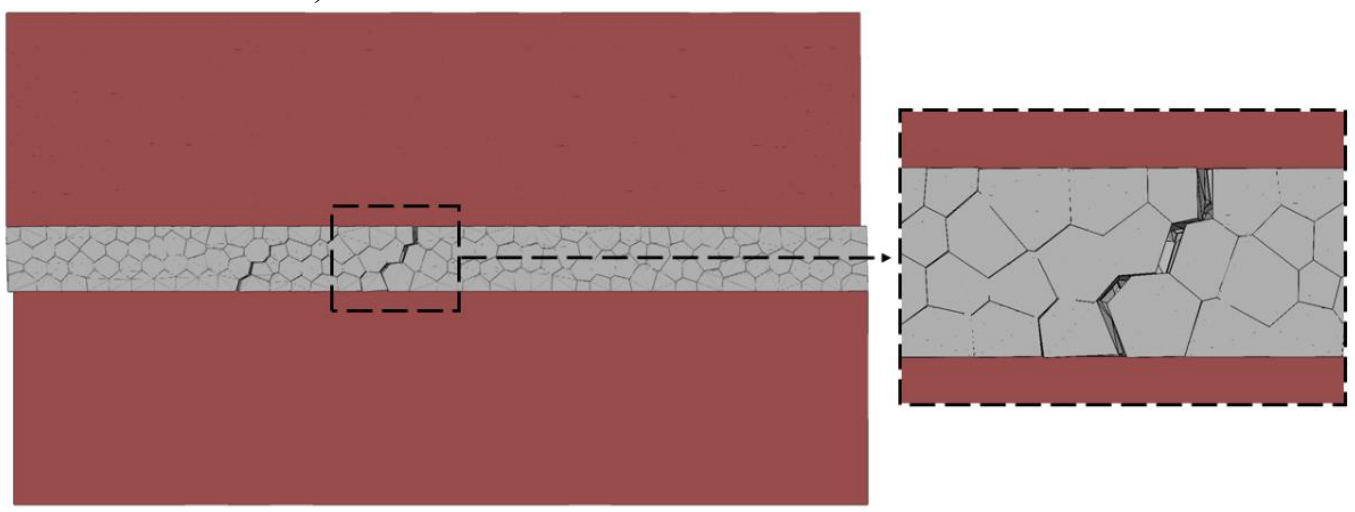

b) Medium mortar under normal stress $1 \mathrm{MPa}$

Figure 8. Examples of failure modes of couplet testing using discrete meso-models.

In conclusion, the proposed contact models, including the mode I and II fracture energies, are validated against experimental studies and allows obtaining fairly close pre- and post-peak responses together with realistic failure modes. Next, more complex fracture mechanism of masonry wallettes subjected to tensile forces parallel to bed joints is examined using the validated softening contact model.

\section{Behavior of masonry wallettes under tension parallel to bed joints}

The direct tension test of masonry prisms and clay bricks is relatively well studied in the literature $[47,48]$; however, there exist few research studies investigating the influence of tensile forces parallel to bed joints. In this section, the validated contact model (exponential softening) in 
shear is used together with the exponential softening model in tension to simulate the tensile test of masonry wallettes parallel to bed joints.

The experimental study presented by Backes [25], consisting of different types of brick and mortar combinations, is utilized to benchmark the results obtained from the discontinuum analyses. During the comprehensive experimental campaign, it is aimed to investigate the relationship between the tensile strength of masonry, its constituents and bonding properties. For detailed information about the test program, the readers are referred to [49]. The illustration of the test setup is shown in Figure 9, made up of four courses of units with brick dimensions of $240 \mathrm{~mm} \times 115$ $\mathrm{mm} \times 113 \mathrm{~mm}$. No confining stresses are considered on the masonry wallette and the load is applied through steel plates uniaxially. In the computational model, the same loading condition is replicated by setting a certain horizontal displacement rate $(1 \mathrm{~mm} / \mathrm{s})$ on one side of the wallette to apply the uniaxial elongation to the specimen, whereas horizontal deflections are restricted at the gridpoints on the opposite side of the specimen. During the analysis, the reaction forces are recorded from the gridpoints, in which the displacement rates are assigned, and extracted at each time step by the implemented subroutine in the software based on FISH functions (an executable programming language in 3DEC).

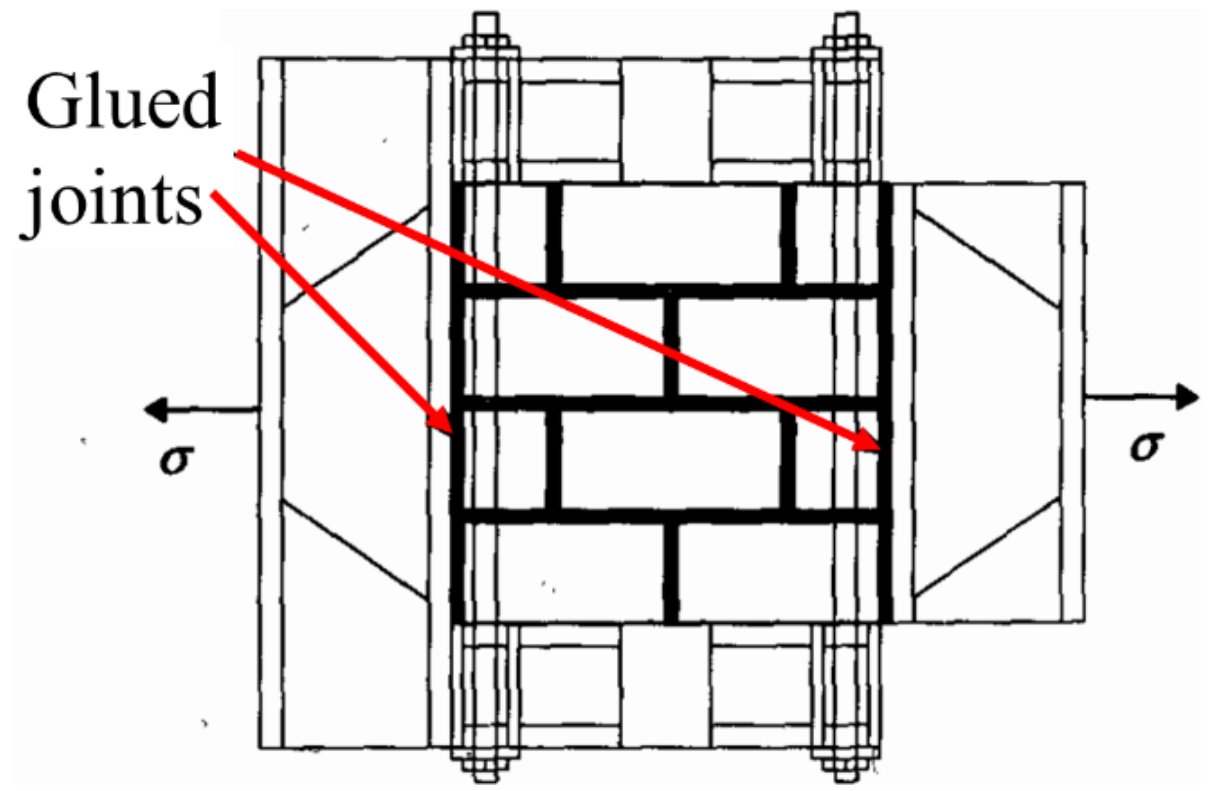

Figure 9. Tensile test of masonry wallette parallel to bed joint [50]. 
Two distinctive failure patterns are observed during the experiment depending on the strength difference between the brick and mortar. The first failure mode indicates step-wise (or zigzag) cracks passing through the bed and head joints, which is likely when mortar is significantly weaker than units. The second type of failure goes through the head joints and bricks. Next, these two failure modes, corresponding to different stress-displacement responses, are studied numerically utilizing the proposed discrete meso-models .

\subsection{Discontinuum Modeling of Failure Mode 1 (Stepwise cracks)}

In the first model, a relatively high tensile strength is considered at the unit, $\left(f_{T}\right)_{\text {Brick }}: 1.44 \mathrm{MPa}$ in order to replicate a high strength brick compared to unit-mortar interface combination, given in [25]. On the other hand, elastic-softening behavior is assigned in tension and shear directions at the interaction surfaces among the units. The mode-I and II fracture energies are assumed according to suggestions given in [51] due to the absence of data. Contact properties can be found in Table 3 .

Table 3. Contact properties (Strong brick \& weak bond)

\begin{tabular}{ccccc}
$k_{n}(\mathrm{~Pa} / \mathrm{m})$ & $k_{S}(\mathrm{~Pa} / \mathrm{m})$ & $f_{T}(\mathrm{~Pa})$ & $\phi_{0}\left({ }^{\circ}\right)$ & $\psi\left({ }^{\circ}\right)$ \\
\hline $167 \mathrm{e}+9$ & $k_{n} / 2(1+v)$ & $0.1 \mathrm{e}+6$ & 45 & 2 \\
$c_{0}(\mathrm{~Pa})$ & $c_{\text {res }}(\mathrm{Pa})$ & $\phi_{\text {res }}\left({ }^{\circ}\right)$ & $G_{f}^{I}(\mathrm{~N} / \mathrm{m})$ & $G_{f}^{I I}(\mathrm{~N} / \mathrm{m})$ \\
\hline $1.5 f_{T}$ & $0.01 c_{0}$ & 36 & 5 & 15
\end{tabular}

In Figure 10, stress-displacement behavior obtained from the meso-model with the proposed contact models are compared with the experimental result. It is recognized that the controlling failure mechanism yields residual stress indicating shear failure at the bed joints together with the tensile cracks at the head joints. 


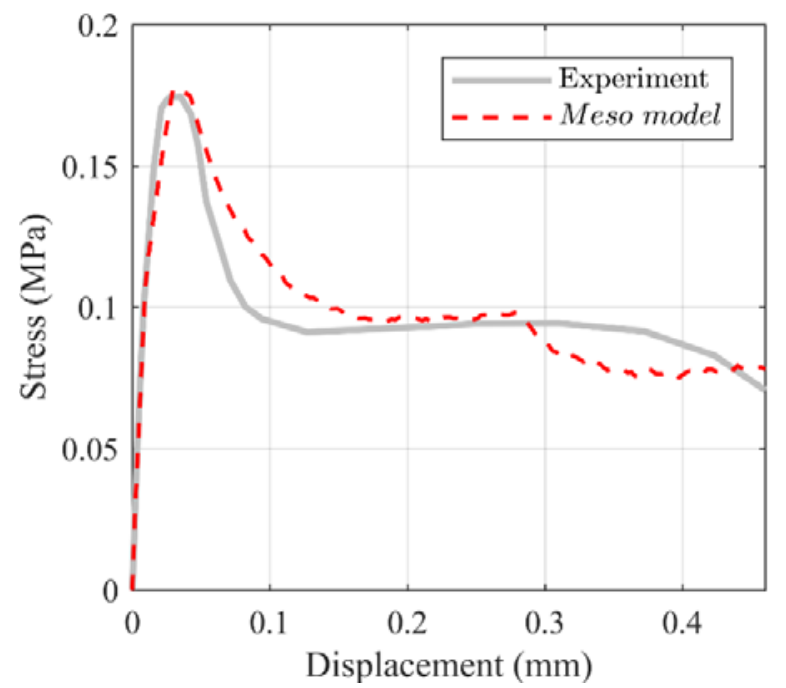

Figure 10. Comparison of the experimental and numerical results (failure mode -1).

An identical failure mode is found in the numerical model when compared with the experiment, where the combination of tensile cracks at the head joint and shear failure at the bed joints are observed, as shown in Figure 11. There is no damage recorded in the bricks during the pre- and the post-peak response of the material, which corresponds to typical strong brick - weak mortar joint behavior.
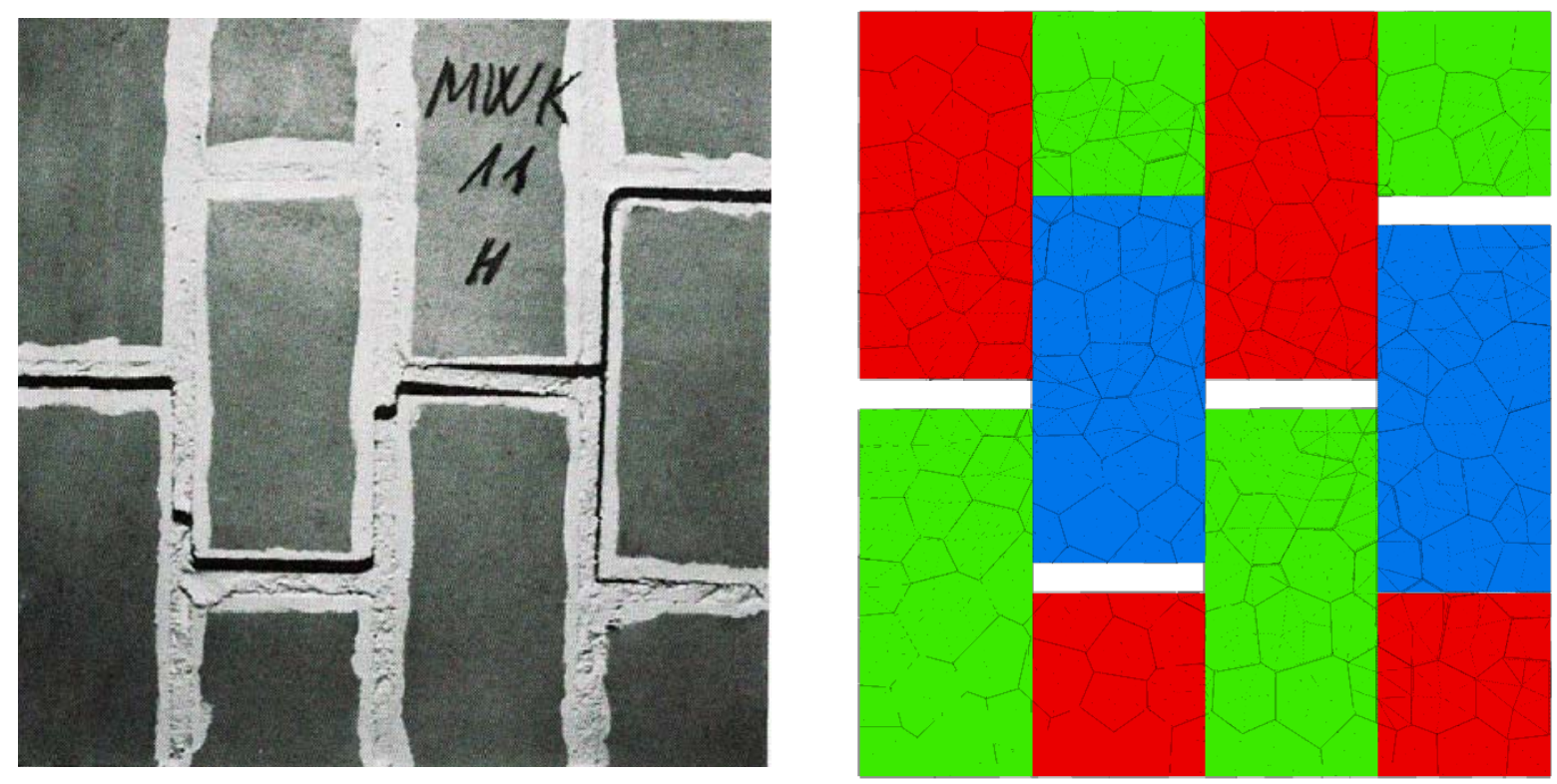

Figure 11. Failure mechanism mode 1; Left: Experiment [25], Right: Numerical Prediction. 
In shear failure, dilatancy (i.e., denoted by dilatancy angle, $\psi$, as the ratio between normal and shear displacements) may play an important role in the macro behavior depending on the surface roughness of the unit-mortar interface. However, it is quite difficult to capture this behavior in the experiment and mostly, the results are quite scattered. According to shear tests performed by Pluijm [52], two tendencies for the dilation angle was observed; i) gradually decreases to zero under incrementally applied shear displacement, ii) remains approximately constant, then, goes down to zero. The latter one is assumed in the present research considering the fact that this type of failure could happen due to combined bond and mortar failure rather than pure shear, as previously mentioned by Pluijm [52]. The pronounced effect of dilatancy can be seen beyond the ultimate stress in Figure 12, when this parameter is varied as 0, 2, and 4 degrees.

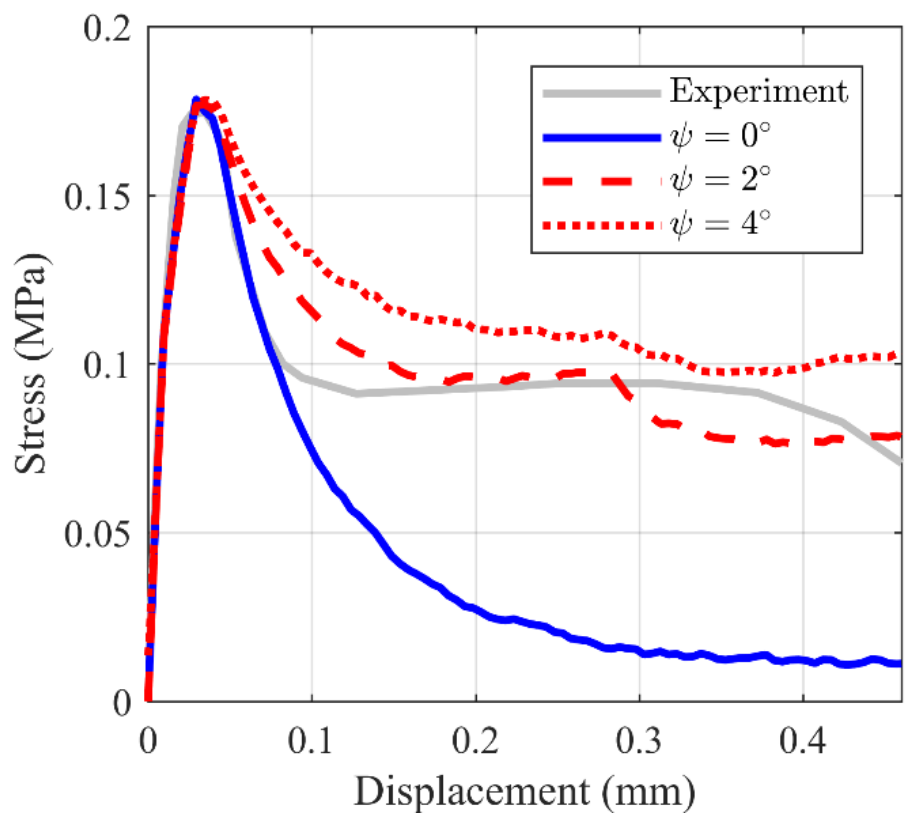

Figure 12. Influence of dilation at the contact surface between the units.

\subsection{Discontinuum Modeling of Failure Mode 2 (Cracking at bricks and head -joints)}

In the second model, the same initial contact stiffnesses are used $\left(k_{n}\right.$ and $\left.k_{s}\right)$, however, different nonlinear contact parameters and fracture energies are assigned. Thus, it is aimed to 
capture the strong bond with comparatively weak bricks action in the numerical model. The nonlinear input contact parameters are given in Table 4. No residual cohesion is considered in the masonry units. The tensile and shear fracture energies are assumed as 8 and $20 \mathrm{~N} / \mathrm{m}$, respectively.

Table 4. Nonlinear contact parameters.

Interaction within the units

\begin{tabular}{ccccc}
$f_{T}(\mathrm{~Pa})$ & $c_{0}(\mathrm{~Pa})$ & $\phi_{0}\left({ }^{\circ}\right)$ & $c_{\text {res }}(\mathrm{Pa})$ & $\phi_{\text {res }}\left({ }^{\circ}\right)$ \\
\hline $0.25 \mathrm{e}+6$ & $1.5 f_{T}$ & 45 & 0 & 30 \\
$f_{T}(\mathrm{~Pa})$ & \multicolumn{2}{c}{ Interaction between the units } \\
\hline $0.20 \mathrm{e}+6$ & $c_{0}(\mathrm{~Pa})$ & $\phi_{0}\left({ }^{\circ}\right)$ & $c_{\text {res }}(\mathrm{Pa})$ & $\phi_{\text {res }}\left({ }^{\circ}\right)$ \\
\hline & $1.5 f_{T}$ & 45 & $0.01 c_{0}$ & 36
\end{tabular}

In Figure 13, a completely different stress-displacement relationship is observed compared to the first failure mode. The softening post-peak response of the wallette is accompanied with tensile failure within the units and head joints.

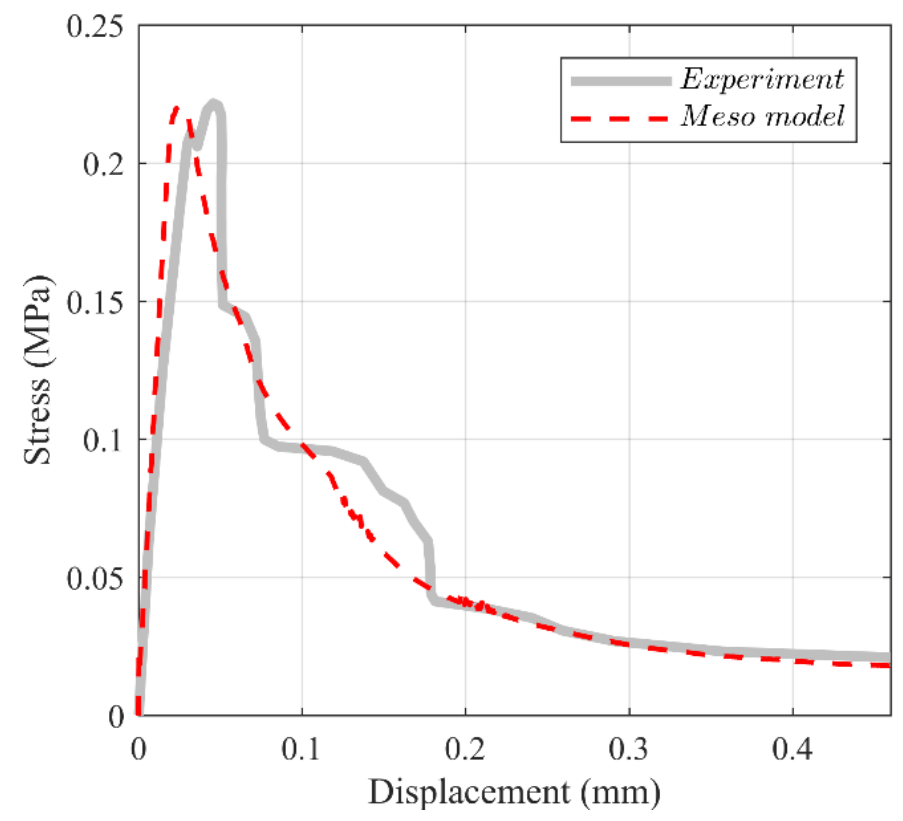

Figure 13. Comparison of the experimental and numerical results (failure mode -2 ). 
Note that a similar cracking mechanism is observed in the discrete element model and the experiment, as shown in Figure 14, where the cracks follow the head joints and bricks (roughly through the mid-length of the brick). This mode results in steep softening since the governing fracture mechanism depends on the tensile response of the mortar-joint and bricks (see Figure 13). Hence, the proposed modeling strategy can predict the actual behavior of the weak brick - strong bond masonry assemblages.
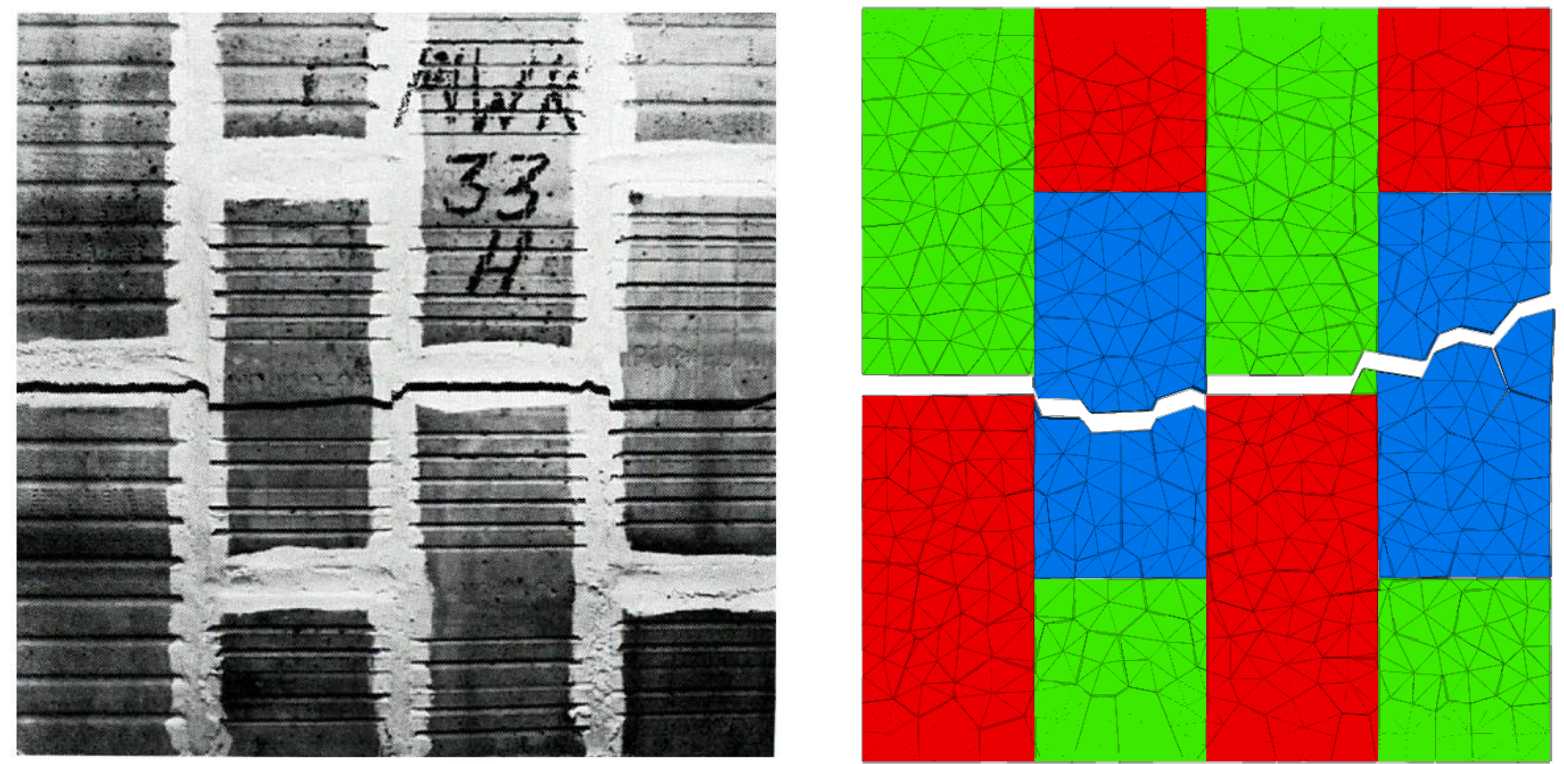

Figure 14. Failure mechanism mode 2; Left: Experiment [25], Right: Numerical Prediction.

\section{Influence of Fracture Energy and Block Size in Masonry Wallettes under Direct Tension}

The validated computational models are further utilized to predict macro behavior of the examined masonry wallettes (both for failure mode 1 and 2) using different fracture energies $\left(G_{f}^{I}\right.$ and $G_{f}^{I I}$ ) and different block sizes. The fracture energy values used for the benchmark study is taken into account as the reference in the sensitivity analyses.

In Figure 15, the effect of various block sizes on the stress-displacement behavior is given where the assigned contact normal stiffness for coarse (218 blocks), medium ( 335 blocks) and fine (540 blocks) are 167, 200 and $250 \mathrm{GPa} / \mathrm{m}$, respectively. Identical nonlinear contact parameters are 
utilized that are given in the previous section. Although, there is no response change observed in the failure mode 1 (zigzag cracks along the head and bed joints), slightly different curves are found due to the variation of contact stress distribution among the blocks (Figure 15a). Moreover, the same trend can be observed in the failure mode 2 since the cracks propagate through the irregularly shaped polyhedral blocks replicating the masonry units (see Figure 15b). There is no difference in the fracture pattern due to block size in failure mode 2 , indicating almost vertical crack at the midlength of the specimen (Figure 16). Thus, according to the numerical investigation, the results do not demonstrate a severe block size dependency and capacity difference in the computational models. Further, it is concluded that the meso-model consisting of coarse blocks provide enough accuracy both for failure mechanism and the material behavior when it is compromised with the computational cost.

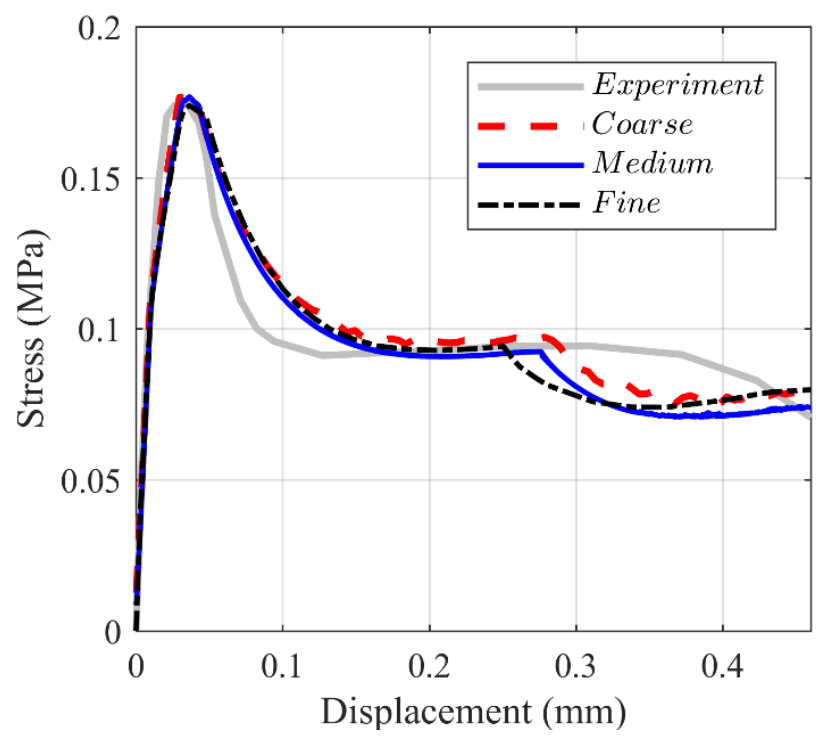

a) Masonry wallette: Failure mode 1

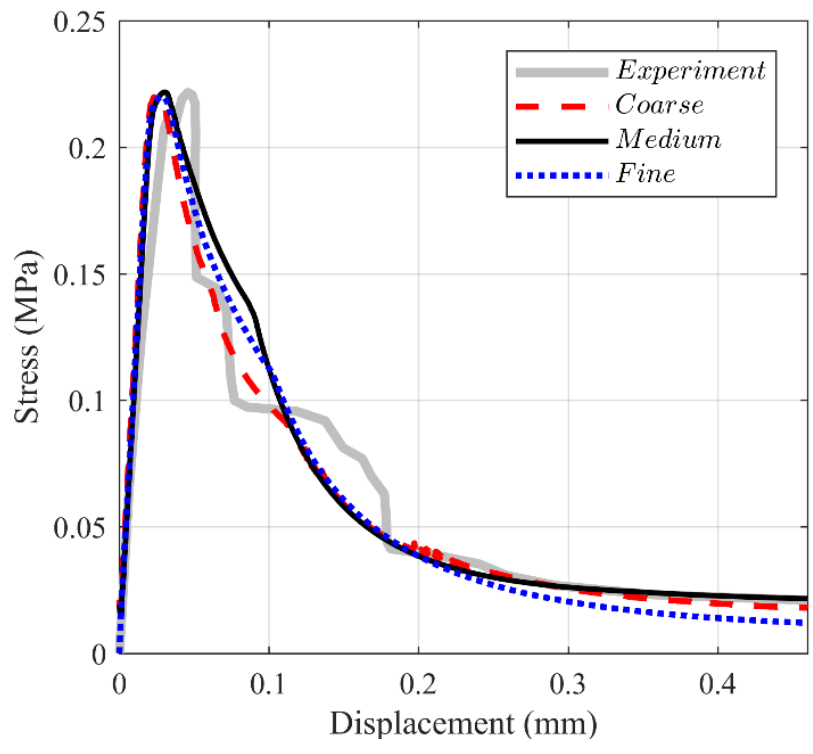

b) Masonry wallette: Failure mode 2

Figure 15. Influence of the block size on the macro behavior of the wallette. 


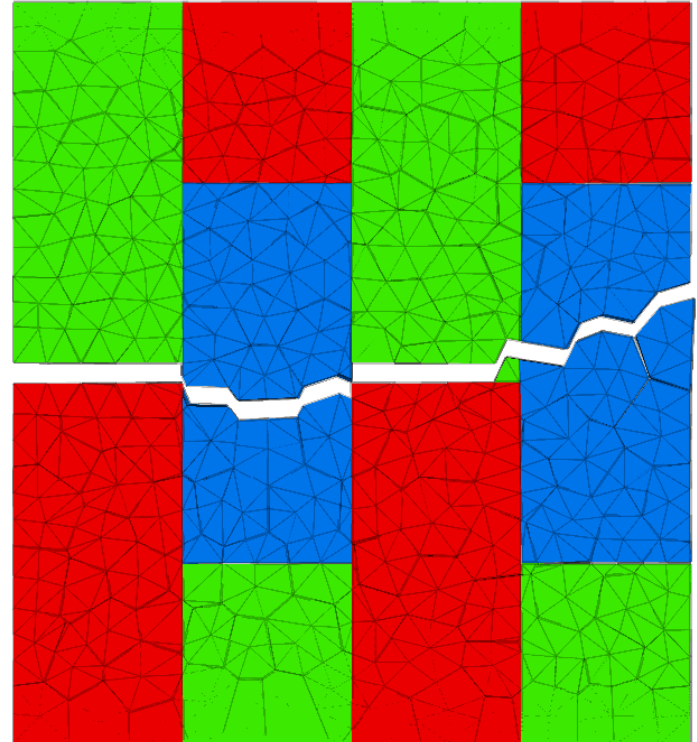

a) Coarse blocks (Failure mode - II)

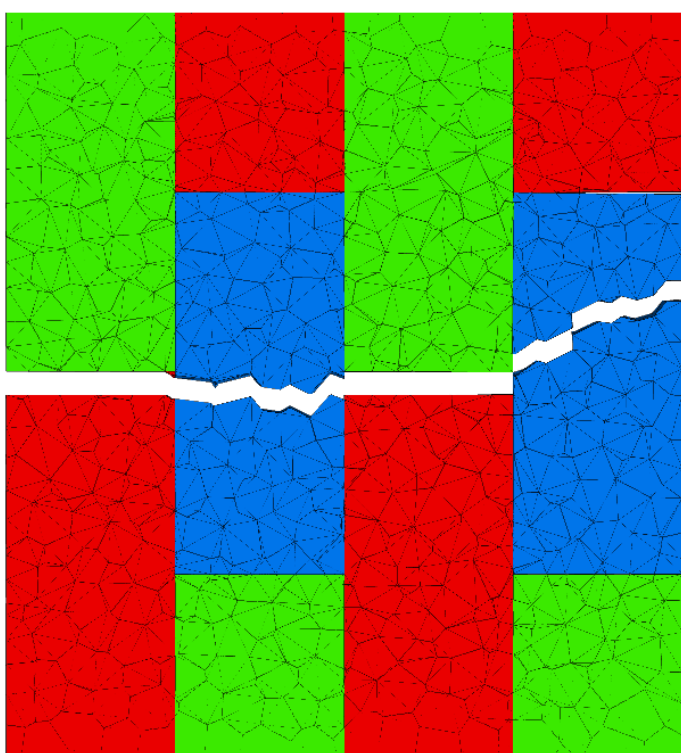

b) Fine blocks (Failure mode - II) Figure 16. Fracture patterns obtained from coarse and fine discrete meso-models.

A parametric study is also performed on $G_{f}^{I}$ and $G_{f}^{I I}$ since the masonry constituents generally present a large scatter of mechanical properties including the fracture energy. Fist, the failure type 1 is taken into consideration and only the interface fracture energies are varied since the failure occurs only at the head and bed joint interfaces. Both interface tensile and shear fracture energies have an important role on the macro behavior of the discrete meso-models. Since the zigzag failure pattern only occurs at the interfaces (which is assumed as flat surface), smooth convergence to residual stresses are obtained for higher $G_{f}^{I}$ and $G_{f}^{I I}$, given in Figure 17. The presented results should be considered as the numerically estimated envelope as similarly obtained via experiments, due to heterogeneous and nonlinear nature of the masonry. 

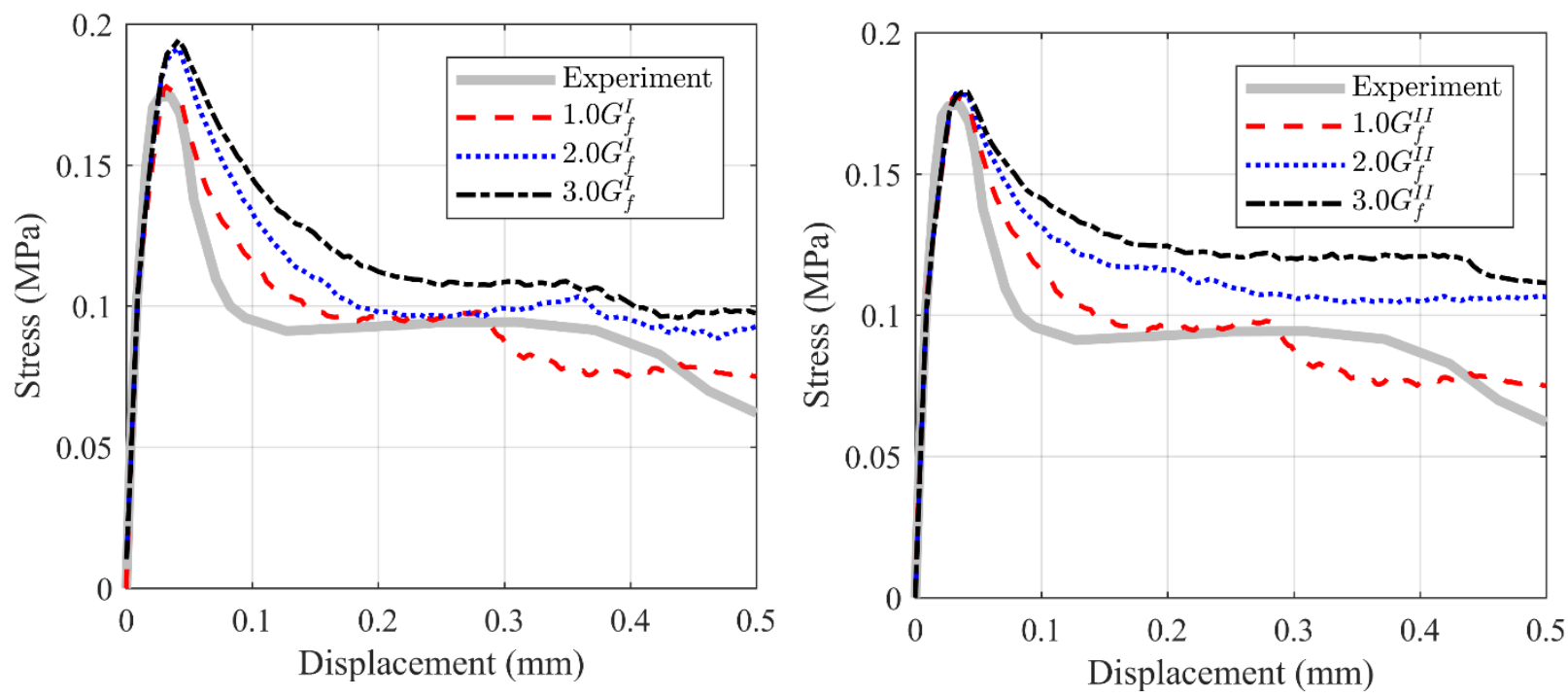

Figure 17. Influence of $\left(G_{f}^{I}\right)_{\text {interface }}$ and $\left(G_{f}^{I I}\right)_{\text {interface }}$ in failure mode 1.

In the second failure mode, sensitivity analyses are performed by considering the mode I and II fracture energies only for at the masonry unit because there was no sliding (or shear) failure observed at the head joints during the analyses. In Figure 18a, a drastic response change on the macro response of the discrete meso-model can be found once relatively higher tensile fracture energy is considered in the unit (i.e. $\left.\left(G_{f}^{I}\right)_{\text {Brick: }} 2\left(G_{f}^{I}\right)_{\text {Interface }}\right)$. Since the failure mode is mainly controlled by the cracking at the head joints and in the masonry units, overall energy dissipation is directly influenced by the mechanical properties of the unit (or referred to as brick). This situation reflects on the crack propagation and fracture surface in the masonry wallette, where the tensile failure mode in the bricks may be seen in Figure 19. Moreover, the increase in $\left(G_{f}^{I I}\right)_{\text {Brick }}$ provides higher residual stresses due to crack face bridging, which is an inherent feature of the heterogeneous material structure [53], as shown in Figure 18b. Therefore, it is numerically demonstrated that the variation in the $\left(G_{f}^{I}\right)_{\text {Brick }}$ (especially higher tensile fracture energies compared to interface) may result in unexpected softening behavior and change the failure pattern in masonry wallettes in case of strong bond condition. Further, the proposed modeling strategy incorporating the softening contact models and semi-rigid polyhedral blocks in DEM captures the overall macro behavior of the composite action of masonry with a realistic fracture pattern. 


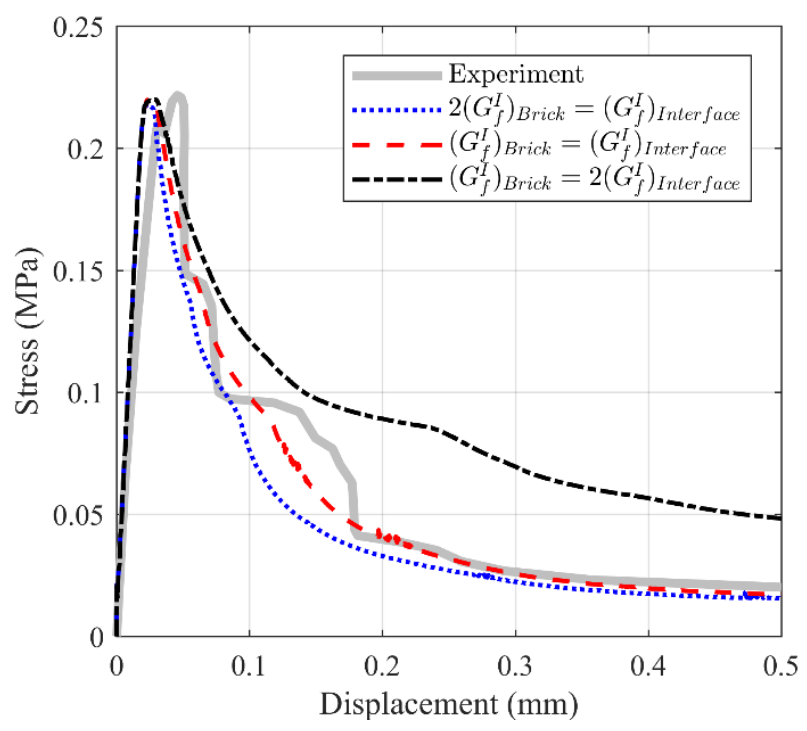

a) Sensitivity analyses on the $\left(G_{f}^{I}\right)_{\text {Brick in }}$ failure mode 2 .

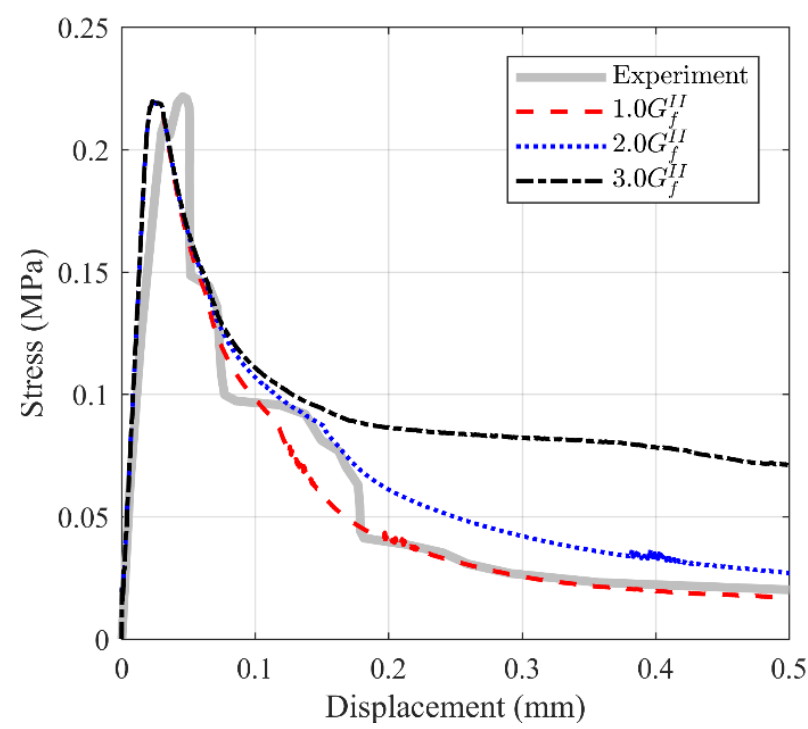

b) Influence of the $\left(G_{f}^{I I}\right)_{\text {Interface }}$ of the brick in failure mode 2

Figure 18 . Sensitivity analyses on the $\left(G_{f}^{I}\right)_{\text {Brick }}$ in failure mode 2.
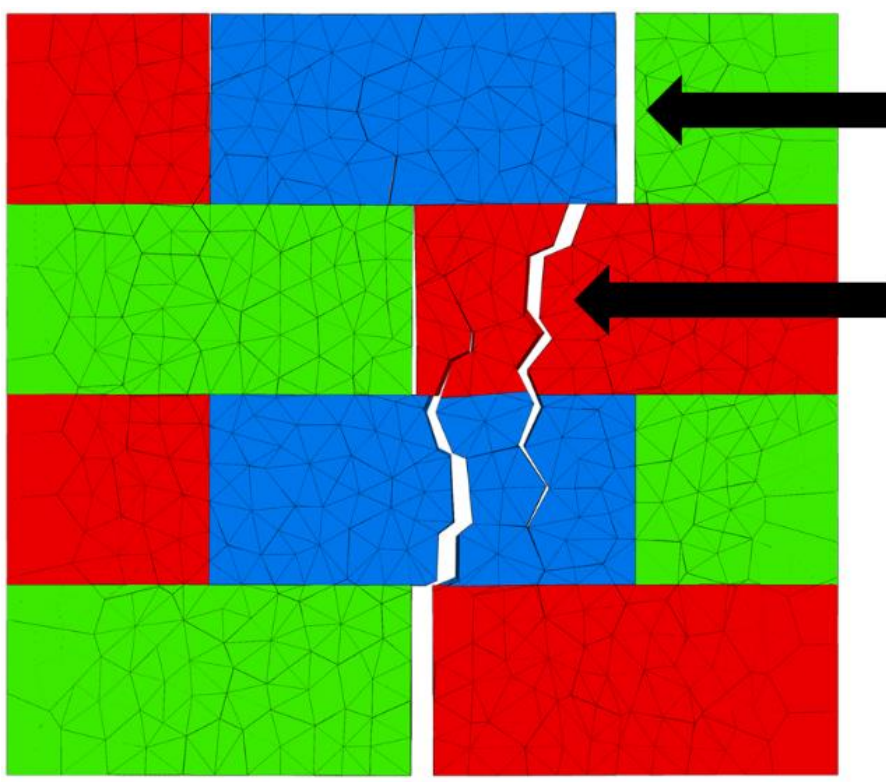

\section{Failure at the head joint}

Failure in the brick

Figure 19. Failure mode of the masonry wallette $\left(G_{f}^{I}\right)_{\text {unit }}: 20 \mathrm{~N} / \mathrm{m},\left(G_{f}^{I}\right)_{\text {Brick: }} 2\left(G_{f}^{I}\right)_{\text {Interface }}$.

\section{Flexural Behavior of Masonry Wallettes}

As a final validation study, the horizontal bending of unreinforced masonry walls is analyzed to extend the applicability of the proposed modeling strategy in three dimensions (3D). Post- 
earthquake observations and laboratory experiments indicate that unreinforced masonry walls subjected to out-of-plane loadings fail either in stepped (or zig-zag) cracking through the unitmortar interface, or a straight line of failure by cracking the units and passing through the head joints [41]. Hence, it is aimed to capture these two distinctive failure modes of unreinforced masonry walls numerically via proposed discrete meso-models. Note that these two types of failure may occur simultaneously as mixed failure mode or individually due to many parameters, such as variability in the mechanical properties of masonry constituents, boundary conditions, quality of workmanship, etc.

In the present research, comprehensive experimental work performed by Willis [27] is used to benchmark the computational models, in which masonry wallettes were tested under four-point bending. Different mortar batches with clay brick combinations were tested during the experimental campaign. The dimensions of the wallettes, built with clay bricks $(230 \times 65 \times 114$ $\mathrm{mm}^{3}$ : length $\times$ height $\times$ wide) and the test setup are presented in Figure 20, including the imposed pre-compression stress. There are approximately ten contact points considered shared by the two discrete blocks along the thickness of the wallette to obtain proper flexural stress distribution, as suggested by $[1,24]$.

Here, two pre-compression stress states are applied in the numerical model; $\sigma=0$ and $\sigma=$ $0.25 \mathrm{MPa}$. The stiffness of the masonry is determined as $E=15 \mathrm{GPa}$ that is the average number provided in the benchmark study. Accordingly, normal and shear contact stiffnesses are determined as $k_{n}=250 \mathrm{e}+9(\mathrm{~Pa} / \mathrm{m})$ and $k_{s}=104 \mathrm{e}+9(\mathrm{~Pa} / \mathrm{m})$, respectively, by taking the average thickness of the fracture zone as $60 \mathrm{~mm}$. Also, the non-linear contact parameters are estimated based on the reference work. In Table 5, the assigned contact properties are presented. It is worth noting that higher mode II fracture energy (i.e., $90 \mathrm{~N} / \mathrm{m}$ ) is assigned for the interface between the units to address the influence of pre-compression. During the analyses, only the roller supports are considered at both sides of the wallette, whereas in the case of $\sigma>0$, the bottom nodes are restricted in the direction of the pre-stress. Dilation angle is set to zero. 


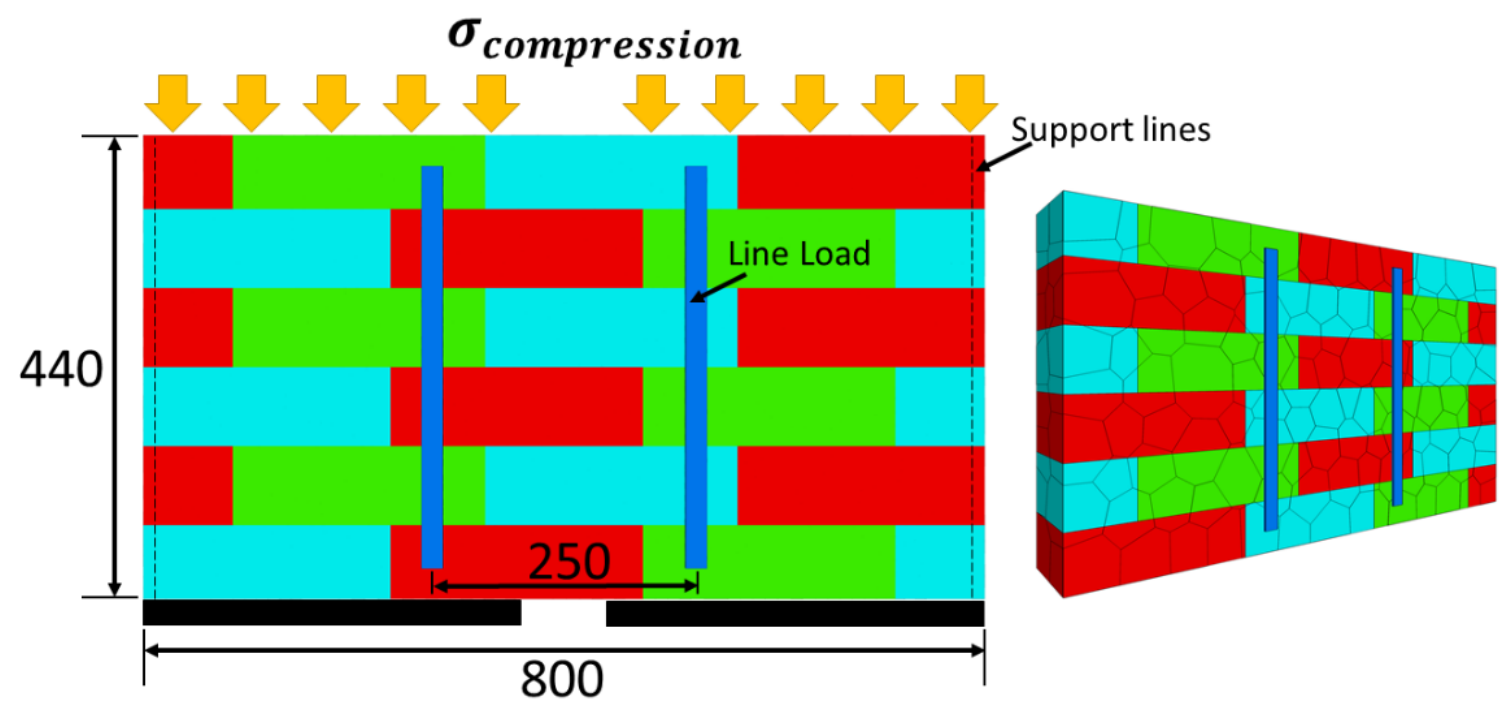

Figure 20. Representation of the test setup (Dimensions are in $\mathrm{mm}$ ).

Table 5. Contact properties used in the discrete meso-model of masonry wallette (* : precompression).

Interaction within the units

\begin{tabular}{ccccccc}
$f_{T}(\mathrm{~Pa})$ & $c_{0}(\mathrm{~Pa})$ & $\phi_{0}\left(^{\circ}\right)$ & $c_{\text {res }}(\mathrm{Pa})$ & $\phi_{\text {res }}\left({ }^{\circ}\right)$ & $G_{f}^{I}(\mathrm{~N} / \mathrm{m})$ & $\mathrm{G}_{\mathrm{f}}^{\mathrm{II}}(\mathrm{N} / \mathrm{m})$ \\
\hline $3.0 \mathrm{e}+6$ & $1.5 f_{T}$ & 45 & $0.01 c_{0}$ & 36 & 50 & 180 \\
$f_{T}(\mathrm{~Pa})$ & $c_{0}(\mathrm{~Pa})$ & $\phi_{0}\left(^{\circ}\right)$ & $c_{\text {res }}(\mathrm{Pa})$ & $\phi_{\text {res }}\left({ }^{\circ}\right)$ & $G_{f}^{I}(\mathrm{~N} / \mathrm{m})$ & $\mathrm{G}_{\mathrm{f}}^{\mathrm{II}}(\mathrm{N} / \mathrm{m})$ \\
\hline $0.30 \mathrm{e}+6$ & $1.5 f_{T}$ & 45 & $0.01 c_{0}$ & 36 & 8 & $40,90^{*}$
\end{tabular}

In Figure 21, the predicted macro behavior of the unreinforced masonry wallette is compared with the experimental results, where the deflections are recorded at the mid-span. It can be seen that the numerically obtained curves exhibit a similar trend and capacity with the experiments both for $\sigma=0$ and $\sigma=0.25 \mathrm{MPa}$. 


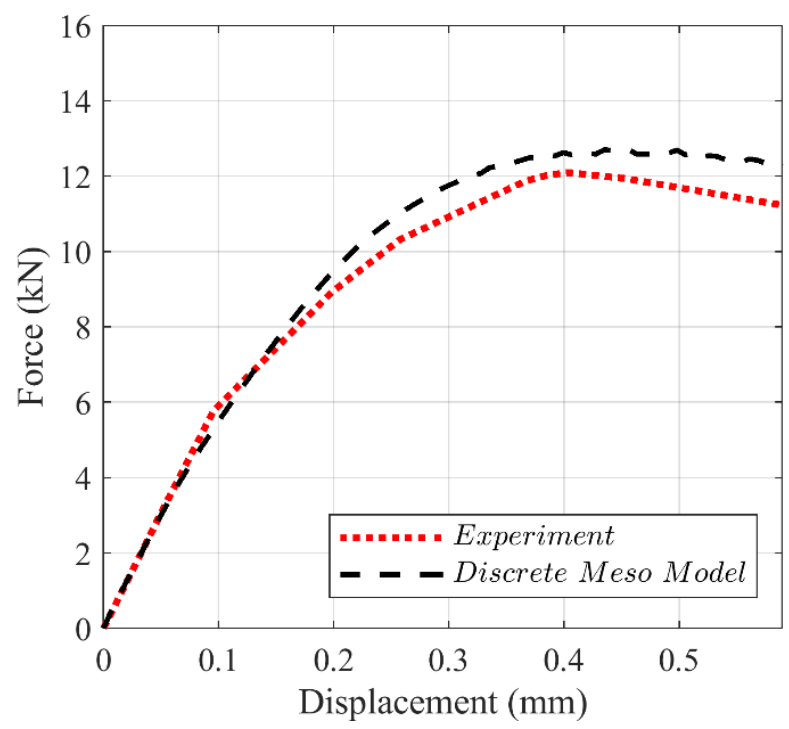

a) Force-displacement curves: $\sigma=0$

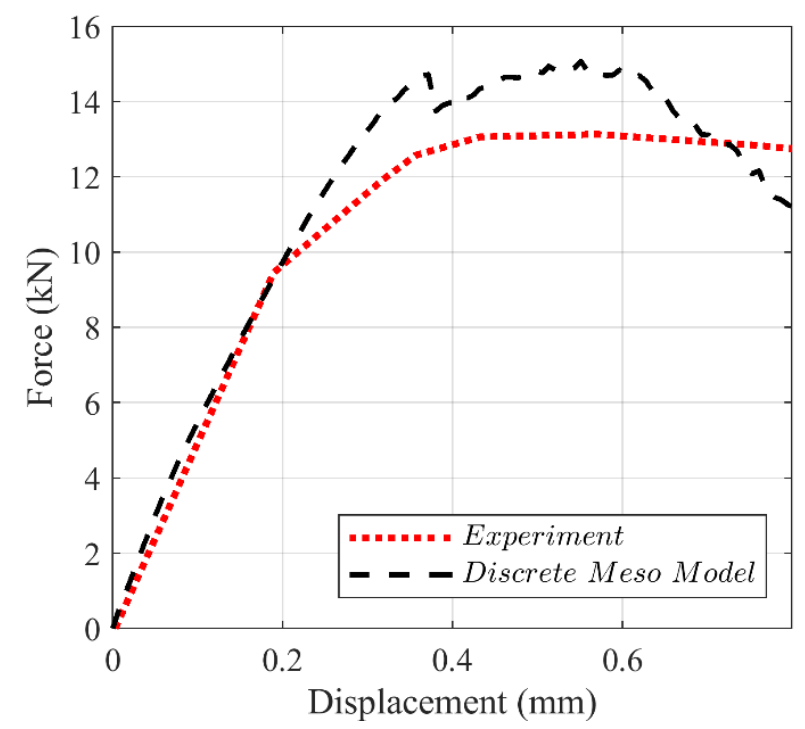

b) Force-displacement curves: $\sigma=0.25 \mathrm{MPa}$

Figure 21. Experimental and numerically estimated force-displacement behaviors for the 4-point bending test.

As discussed in the experimental study, the failure mechanism was changed from stepped to mixed failure mode depending on the vertical pre-compression stress. The effect of compressive pressure can clearly be observed on the fracture mechanism, as given in Figure 22. Similarly, this phenomenon is captured numerically via the proposed modeling strategy (see Figure 22), where the possible tensile cracking within the masonry units and the unit-mortar interface are captured. However, it is important to note that the variation in the material properties (within a certain interval) is not taken into consideration in the discrete meso-model. In other words, the same tensile strength for the contacts within the units is employed. Therefore, the qualitatively satisfying results are found compared to the experimental findings in terms of crack pattern. 

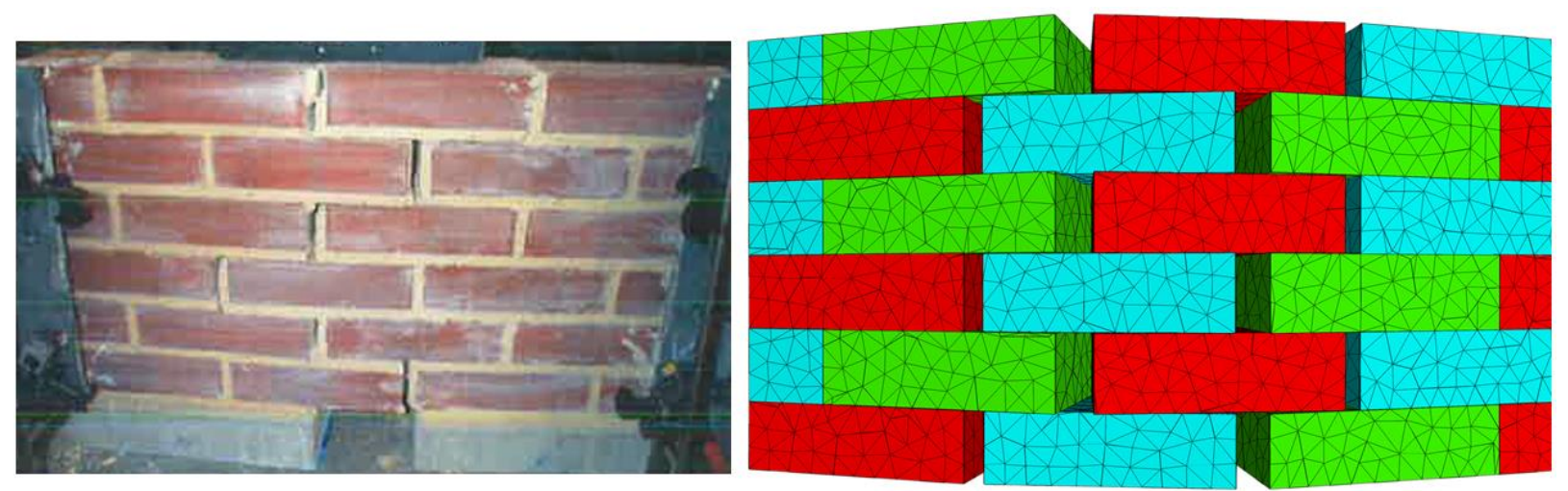

a) .Head joint failure due to flexural tension; Left: Experiment [27], Right: Discrete mesomodel $\left(\sigma_{\text {compression }}=0\right)$.
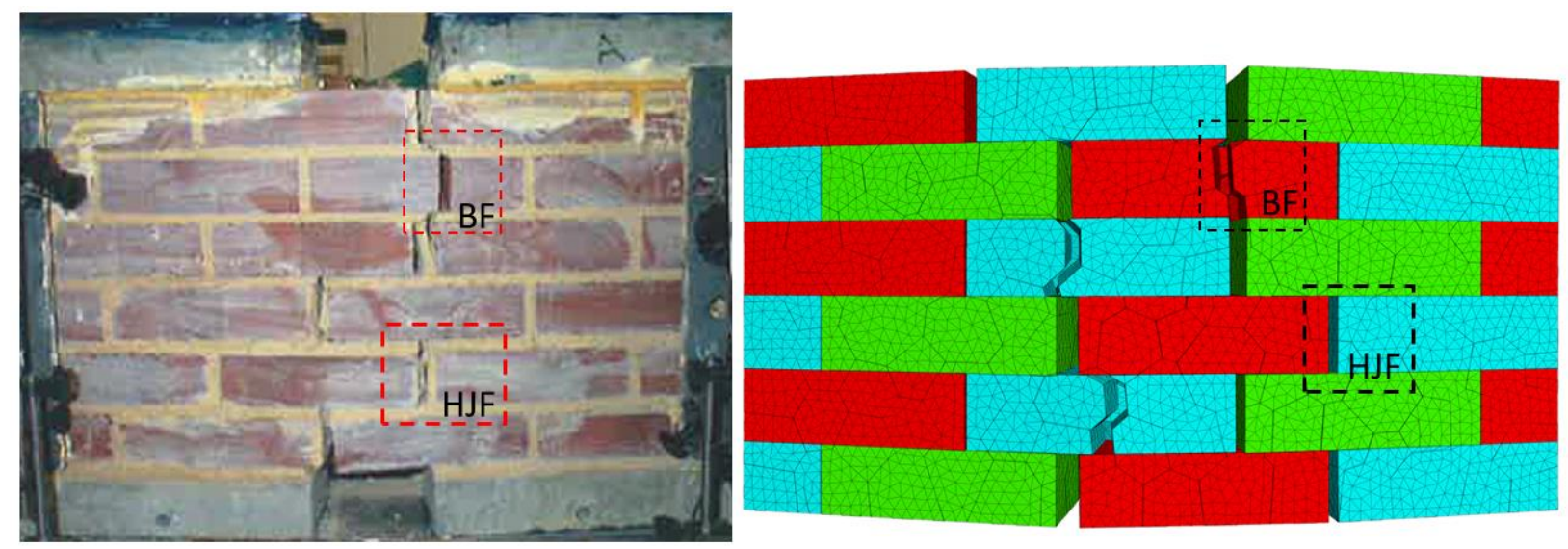

b) Mixed failure mode including cracking of brick and head joint opening; Left: Experiment (BF: Brick failure, HJF: Head joint failure) [27], Right: Discrete meso-model ( $\sigma_{\text {compression }}=$ $0.25 \mathrm{MPa})$.

Figure 22. Comparison of different flexural failure modes of masonry wallettes between experiments and discrete meso-models.

\section{Conclusions}

In this research, new elastic-softening contact constitutive laws that incorporate necessary fracture energies $\left(G_{f}^{I}\right.$ and $\left.G_{f}^{I I}\right)$ are implemented into the dynamic solution algorithm of DEM. Three different tension and shear softening models (linear, polynomial and exponential) are proposed depending on the desired level of accuracy from the numerical model. Furthermore, based on the experimentally observed fracture patterns, two discontinuum meso-models are prepared where mortar joint or masonry units are replicated explicitly. According to the results of the analyses, the following conclusions are derived. 
- The proposed contact models performed well to capture the post-peak regime of the material behavior both in tension and/or shear and become a better alternative to the commonly used simple elasto-plastic contact constitutive laws in DEM.

- Dependency on the block size (or the number of contact points) in DEM using brittle fracture models, recently highlighted by Sarhosis et al. [39], is considerably minimized due to consideration of essential fracture energies at the contact constitutive law based on the point contact hypothesis.

- The randomly generated 3D polyhedral blocks, using an open-source software NEPER, provide realistic fracture mechanisms both for mortar and masonry units compared to experimental results, as demonstrated in $2 \mathrm{D}$ and $3 \mathrm{D}$ problems.

- Due to large variations in the mechanical properties of masonry constituents, it is suggested to obtain an envelope of various test results and fracture patterns. This situation is numerically confirmed via proposed discrete meso-models of masonry wallette with different energy dissipation capacities at the interface and units.

- Finally, the proposed modeling strategy provides essential information such as strength, stress-displacement behavior and fracture mechanism of masonry numerically, thus it provides an alternative solution to costly experimental programs in parametric investigations.

In a future study, the proposed discrete meso-modeling strategy will be extended to threedimensional large-scale multi-leaf masonry walls to explore structural behavior (both in- and outof-plane) and the progressive cracking mechanism.

\section{Conflict of Interest}

The authors declare that they have no conflict of interest. 


\section{References}

1. Pulatsu B, Bretas EM, Lourenço PB (2016) Discrete element modeling of masonry structures: Validation and application. Earthquakes Struct 11:563-582. https://doi.org/10.12989/eas.2016.11.4.563

2. Pulatsu B, Erdogmus E, Bretas EM (2018) Parametric Study on Masonry Arches Using 2D Discrete-Element Modeling. J Archit Eng 24:04018005. https://doi.org/10.1061/(ASCE)AE.1943-5568.0000305

3. Malomo D, DeJong MJ, Penna A (2019) Influence of Bond Pattern on the in-plane Behavior of URM Piers. Int J Archit Herit 00:1-20. https://doi.org/10.1080/15583058.2019.1702738

4. Napolitano RK, Glisic B (2019) Understanding the function of bonding courses in masonry construction: An investigation with mixed numerical methods. J Cult Herit 39:120-129. https://doi.org/10.1016/j.culher.2019.03.007

5. Roca P, Cervera M, Gariup G, Pela L (2010) Structural analysis of masonry historical constructions. Classical and advanced approaches. Arch Comput Methods Eng 17:299-325. https://doi.org/10.1007/s11831-010-9046-1

6. Pelà L, Cervera M, Roca P (2013) An orthotropic damage model for the analysis of masonry structures. Constr Build Mater 41:957-967. https://doi.org/10.1016/j.conbuildmat.2012.07.014

7. Lourenço PB, Rots JG, Blaauwendraad J (1998) Continuum model for masonry: Parameter estimation and validation. J Struct Eng 124:642-652. https://doi.org/10.1061/(ASCE)07339445(1998)124:6(642)

8. Saloustros S, Cervera M, Pelà L (2018) Tracking multi-directional intersecting cracks in numerical modelling of masonry shear walls under cyclic loading. Meccanica 53:17571776. https://doi.org/10.1007/s11012-017-0712-3

9. Drougkas A, Roca P, Molins C (2015) Numerical prediction of the behavior, strength and elasticity of masonry in compression. Eng Struct 90:15-28. https://doi.org/10.1016/j.engstruct.2015.02.011

10. Drougkas A, Roca P, Molins C (2016) Nonlinear micro-mechanical analysis of masonry periodic unit cells. Int J Solids Struct 80:193-211. https://doi.org/10.1016/j.ijsolstr.2015.11.004

11. Pina-Henriques J, Lourenço PB (2006) Masonry compression: A numerical investigation at the meso-level. Eng Comput (Swansea, Wales) 23:382-407. https://doi.org/10.1108/02644400610661163

12. Attard MM, Nappi A, Tin-Loi F (2007) Modeling Fracture in Masonry. J Struct Eng 133:1385-1392. https://doi.org/10.1061/(asce)0733-9445(2007)133:10(1385)

13. Lourenço PB, Rots JG (1997) Multisurface interface model for analysis of masonry structures. J Eng Mech 123:660-668

14. Gambarotta L, Lagomarsino S (1997) Damage models for the seismic response of brick masonry shear walls. Part 2 The continuum model and its applications. Earthq Eng Struct Dyn 26:441-462

15. Malomo D, DeJong M, Penna A (2018) Distinct element modelling of the in-plane failure mechanisms of URM walls. In: Proceedings of the 10th International Masonry Conference

16. Pulatsu B, Erdogmus E, Bretas EM, Lourenço PB (2019) In-Plane Static Response of DryJoint Masonry Arch-Pier Structures. In: AEI 2019. American Society of Civil Engineers, 
Reston, VA, pp 240-248

17. Sarhosis V, Garrity SW, Sheng Y (2015) Influence of brick-mortar interface on the mechanical behaviour of low bond strength masonry brickwork lintels. Eng Struct 88:1-11. https://doi.org/10.1016/j.engstruct.2014.12.014

18. Napolitano RK, Glisic B (2019) Methodology for diagnosing crack patterns in masonry structures using photogrammetry and distinct element modeling. Eng Struct 181:519-528. https://doi.org/10.1016/j.engstruct.2018.12.036

19. Smoljanović H, Živaljić N, Nikolić Ž, Munjiza A (2018) Numerical analysis of 3D drystone masonry structures by combined finite-discrete element method. Int J Solids Struct 136-137:150-167. https://doi.org/10.1016/j.ijsolstr.2017.12.012

20. Munjiza A, Smoljanović H, Živaljić N, et al (2019) Structural applications of the combined finite-discrete element method. Comput Part Mech. https://doi.org/10.1007/s40571-01900286-5

21. Smoljanović H, Živaljić N, Nikolić Ž, Munjiza A (2017) Numerical model for confined masonry structures based on finite discrete element method. Int J Eng Model 30:19-35

22. Smoljanović H, Nikolić Ž, Živaljić N (2015) A combined finite-discrete numerical model for analysis of masonry structures. Eng Fract Mech. https://doi.org/10.1016/j.engfracmech.2015.02.006

23. Chen W, Konietzky H, Liu C, et al (2018) Prediction of brickwork failure using discreteelement method. J Mater Civ Eng 30:06018012. https://doi.org/10.1061/(ASCE)MT.19435533.0002431

24. Godio M, Stefanou I, Sab K (2018) Effects of the dilatancy of joints and of the size of the building blocks on the mechanical behavior of masonry structures. Meccanica 53:16291643. https://doi.org/10.1007/s11012-017-0688-z

25. Backes HP (1985) Tensile strength of masonry. In: Proceedings of the 7 th International Brick Masonry Conference. pp 779-790

26. Pluijm R van der (1999) Out-of-Plane Bending of Masonry Behaviour and Strength

27. Willis RC (2004) Design of Unreinforced Masonry Walls for Out-of-plane Loading. University of Adelaide

28. Resende R, Lemos J V., Dinis PB (2014) Application of a discontinuity model with softening to the analysis of dam foundations using the Discrete Element Method. In: 1st International UDEC/3DEC Symposium: Numerical Modelling of Discrete Materials in Geotechnical Engineering, Civil Engineering and Earth Sciences. pp 249-255

29. Cundall PA (1971) A computer model for simulating progressive, large-scale movements in blocky rock systems. In: The International Symposium on Rock Mechanics. pp 47-65

30. Quey R, Dawson PR, Barbe F (2011) Large-scale 3D random polycrystals for the finite element method: Generation, meshing and remeshing. Comput Methods Appl Mech Eng 200:1729-1745. https://doi.org/10.1016/j.cma.2011.01.002

31. Quey R, Renversade L (2018) Optimal polyhedral description of 3D polycrystals: Method and application to statistical and synchrotron X-ray diffraction data. Comput Methods Appl Mech Eng 330:308-333. https://doi.org/10.1016/j.cma.2017.10.029

32. Quey R (2014) Neper Reference Manual 3.5.1

33. Lemos J V. (2019) Discrete Element Modeling of the Seismic Behavior of Masonry Construction. Buildings 9:43. https://doi.org/10.3390/buildings9020043

34. Cundall PA (1988) Formulation of a three-dimensional distinct element model-Part I. A 
scheme to detect and represent contacts in a system composed of many polyhedral blocks. Int J Rock Mech Min Sci Geomech 25:107-116

35. Cundall PA, Detournay C (2017) Dynamic relaxation applied to continuum and discontinuum numerical models in geomechanics. In: Rock Mechanics and Engineering. CRC Press, pp 57-102

36. Hart R, Cundall PA, Lemos J V. (1988) Formulation of a three-dimensional distinct element model-Part II. Mechanical calculations for motion and interaction of a system composed of many polyhedral blocks. Int J Rock Mech Min Sci 25:117-125. https://doi.org/10.1016/0148-9062(88)92294-2

37. Itasca (2004) 3DEC Universial Discrete Element Code Theory and Background. Minneapolis

38. Lemos J V. (2007) Discrete element modeling of masonry structures. Int J Archit Herit 1:190-213. https://doi.org/10.1080/15583050601176868

39. Sarhosis V, Lemos J V. (2018) A detailed micro-modelling approach for the structural analysis of masonry assemblages. Comput Struct 206:66-81. https://doi.org/10.1016/j.compstruc.2018.06.003

40. Itasca Consulting Group Inc. (2013) 3DEC Three Dimensional Distinct Element Code

41. Vaculik J, Griffith MC (2017) Probabilistic Analysis of Unreinforced Brick Masonry Walls Subjected to Horizontal Bending. J Eng Mech 143:04017056. https://doi.org/10.1061/(ASCE)EM.1943-7889.0001266

42. Atkinson RH, Amadei BP, Saeb S, Sture S (1989) Response of masonry bed joints in direct shear. J Struct Eng 115:2276-2296

43. Lourenço PB (1996) Computational strategies for masonry structures. Delft University of Technology

44. Van der Pluijm R (1992) Material properties of masonry and its components under tension and shear. In: Proceedings 6th Canadian Masonry Symposium. Saskatoon, pp 675-686

45. Kazerani T, Zhao J (2010) Micromechanical parameters in bonded particle method for modelling of brittle material failure. Int J Numer Anal Methods Geomech 34:1877-1895. https://doi.org/10.1002/nag.884

46. Pulatsu B, Erdogmus E, Lourenço PB, Quey R (2019) Simulation of uniaxial tensile behavior of quasi-brittle materials using softening contact models in DEM. Int J Fract 217:105-125. https://doi.org/10.1007/s10704-019-00373-x

47. Chiskis A, Parnes R, Slepyan L (1997) Nonlinear behavior of wavy composites under tension. J Mech Phys Solids 45:1357-1392. https://doi.org/10.1016/S0022-5096(96)001184

48. Lourenço PB, Almeida JC, Barros JA (2005) Experimental investigation of bricks under uniaxial tensile testing. Mason Int 18:11-20

49. Backes HP (1985) On the behavior of masonry under tension in the direction of the bed joints. Aachen University of Technology

50. Lourenço PB, Rots JG, Van der Pluijm R (1999) Understanding the Tensile Behavior of Masonry Parallel to the Bed Joints- A Numerical Approach. Mason Int 12:96-103

51. Lourenço PB (2009) Recent advances in masonry structures: Micromodelling and homogenisation, in: Multiscale Modeling in Solid Mechanics: Computational Approaches. In: Multiscale modeling in solid mechanics: computational approaches. pp 251-294

52. Van der Pluijm R, Rutten H, Ceelen M (2000) Shear behaviour of bed joints. In: 12th 
International Brick/Block Masonry Conference. pp 1-14

53. Van Mier JGM, Man H-K (2009) Some Notes on Microcracking, Softening, Localization, and Size Effects. Int J Damage Mech 18:283-309. https://doi.org/10.1177/1056789508097545 